\title{
Effect of thermomechanical processing on evolution of various phases in Ti-Nb alloys
}

\author{
S BANUMATHY, K S PRASAD, R K MANDAL ${ }^{\dagger}$ and A K SINGH* \\ Defence Metallurgical Research Laboratory, Kanchanbagh P.O., Hyderabad 500 058, India \\ ${ }^{\dagger}$ Department of Metallurgical Engineering, Institute of Technology, Banaras Hindu University, \\ Varanasi 221 005, India
}

MS received 28 April 2010; revised 2 November 2010

\begin{abstract}
This paper deals with the effect of thermomechanical processing on microstructural evolution of three alloys, viz. $\mathrm{Ti}-8 \mathrm{Nb}, \mathrm{Ti}-12 \mathrm{Nb}$ and $\mathrm{Ti}-16 \mathrm{Nb}$. The alloys were hot rolled at $800^{\circ} \mathrm{C}$ and then subjected to various heat treatments. Samples from hot-rolled alloys were given solution-treatment in $\beta$ and $\alpha+\beta$ phase fields, respectively followed by water quenching and furnace cooling. The solution-treated alloys were subsequently aged at different temperatures for $24 \mathrm{~h}$. Phases evolved after various heat treatments were studied using X-ray diffractometer, optical, scanning and transmission electron microscopes. The alloy Ti-8Nb exhibits $\alpha$ and $\beta$ phases while the alloys Ti-12Nb and Ti-16Nb show the presence of $\alpha^{\prime \prime}, \beta$ and $\omega$ phases in the as-cast and hot-rolled conditions. The $\beta$ solution treated and water quenched specimen of the alloy Ti-8Nb displays $\alpha^{\prime \prime}$ phase while the alloys Ti-12Nb and Ti-16Nb exhibit $\alpha^{\prime \prime}, \beta$ and $\omega$ phases. The alloy Ti-8Nb shows the presence of $\alpha, \beta$ and $\omega$ phases while those of Ti-12Nb and Ti-16Nb display the presence of $\alpha, \alpha^{\prime \prime}, \beta$ and $\omega$ in $\alpha+\beta$ solution treated and water quenched condition. The observation of $\omega$ phase in solution treated condition depends on the cooling rate and the $\mathrm{Nb}$ content while in the aged specimens, it is governed by aging temperature as well as the $\mathrm{Nb}$ content.
\end{abstract}

Keywords. Heat treatment; Ti-Nb alloys; thermomechanical processing; microstructure; X-ray diffraction.

\section{Introduction}

Titanium and its alloys, owing to their attractive properties are widely used in aerospace applications (Collings 1984; Boyer et al 1994). Efforts over the last four decades have resulted in the development of excellent conventional alloys for application in temperature range between $420 \mathrm{~K}$ (replacing aluminum alloys) and $875 \mathrm{~K}$ (in place of super alloys). In addition, titanium alloys are also widely used as implants in orthopedics, dentistry and cardiology due to their outstanding biomedical compatibility. Eylon et al (1984) reviewed various aspects of development of these alloys. These are grouped into five classes viz. $\alpha$, near $\alpha, \alpha+\beta$, near $\beta$ and $\beta$ depending on the concentration of $\alpha$ and $\beta$ stabilizing elements.

The Ti-Nb binary alloys have been extensively studied as they exhibit several equilibrium and non-equilibrium phases depending on the composition and heat treatments (Collings 1984; Boyer et al 1994). Murray (1987) has given an assessed equilibrium binary phase diagram of $\mathrm{Ti}-\mathrm{Nb}$. A schematic representation of the occurrence of metastable phases such as $\alpha, \alpha^{\prime \prime}$ and $\omega$ for the Ti-transition metal system and related phase field as

\footnotetext{
*Author for correspondence (singh_ashok3@ rediffmail.com)
}

function of temperature and ela ratio is shown elsewhere (Collings 1984; Boyer et al 1994). Although different types of phase transformations involving the occurrence of equilibrium and non-equilibrium phases have been reported in $\mathrm{Ti}-\mathrm{Nb}$ alloys in the range of $0-20$-atom $\% \mathrm{Nb}$, a systematic study on the effect of thermomechanical processing on evolution of various phases appears to be lacking in the literature. This includes investigation pertaining to competing phase transformations between $\beta \rightarrow$ martensite $\left(\alpha\right.$ and $\alpha^{\prime \prime}$ ) and $\beta \rightarrow \omega$, cooling rate dependence of transformation products as well as the effect of aging temperature.

The $\mathrm{Ti}-\mathrm{Nb}$ alloys are most widely used as superconducting materials and also find uses in aerospace applications (Collings 1984; Boyer et al 1994). It is important that the relative phase stability in this system is understood properly. It is well known that the evolution of microstructure and phases in titanium alloys can be controlled by thermomechanical treatment. This investigation is thus undertaken to study the effects of mechanical working and heat treatment on the evolution of structures and microstructures in $\mathrm{Ti}-8 \mathrm{Nb}, \mathrm{Ti}-12 \mathrm{Nb}$ and $\mathrm{Ti}-16 \mathrm{Nb}$ alloys. The $\mathrm{Nb}$ concentrations in the present alloys are greater than the critical limit of $\alpha / \alpha^{\prime \prime}$ transition after $\beta$ solution treatment and water quenching. The $\mathrm{Nb}$ is a well known $\beta$ stabilizer and the presence of $\beta$ phase in the microstructure 
Table 1. Chemical composition of experimental alloys.

\begin{tabular}{lccccc}
\hline & & \multicolumn{3}{c}{ Interstitial contents (ppm) } \\
\cline { 4 - 6 } Alloy & Ti (atom \%) & Nb (atom \%) & Oxygen & Nitrogen & Hydrogen \\
\hline $\mathrm{Ti}-8 \mathrm{Nb}$ & $91 \cdot 7$ & $8 \cdot 3$ & 1150 & 47 & 20 \\
$\mathrm{Ti}-12 \mathrm{Nb}$ & $87 \cdot 9$ & $12 \cdot 1$ & 1197 & 54 & 22 \\
$\mathrm{Ti}-16 \mathrm{Nb}$ & $83 \cdot 6$ & $16 \cdot 4$ & 1010 & 63 & 26 \\
\hline
\end{tabular}

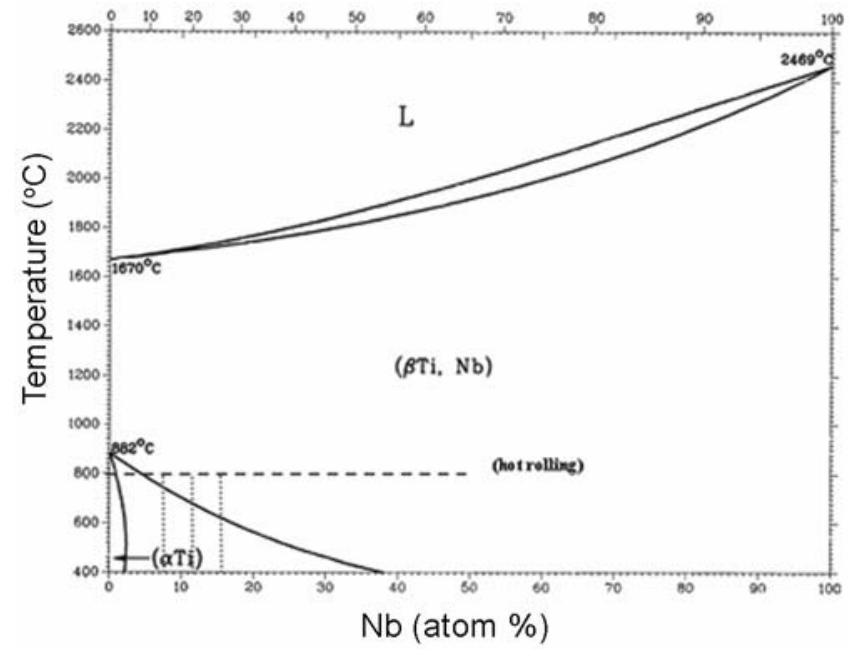

Figure 1. Equilibrium binary phase diagram of $\mathrm{Ti}-\mathrm{Nb}$ system (Murray 1987).

enhances the ability of alloy to harden on subsequent aging (Collings 1984; Boyer et al 1994).

\section{Experimental}

\subsection{Alloy preparation}

Six hundred grams of pancakes of three alloys, Ti-8Nb, $\mathrm{Ti}-12 \mathrm{Nb}$ and $\mathrm{Ti}-16 \mathrm{Nb}$ were prepared by non-consumable vacuum arc melting technique and melting was repeated six times to ensure chemical homogeneity. The analysed compositions of the cast alloys are given in table 1 . The pancakes were, thereafter, subjected to unidirectional hot rolling in the $\beta$ phase field $\left(800^{\circ} \mathrm{C}\right)$ to $80 \%$ reduction and air cooled (AC). The reduction in each pass was around $5 \%$. The equilibrium binary phase diagram of $\mathrm{Ti}-\mathrm{Nb}$ system is shown in figure 1 . The $\beta$ transus temperature obtained by differential scanning calorimetry (DSC) for $\mathrm{Ti}-8 \mathrm{Nb}, \mathrm{Ti}-12 \mathrm{Nb}$ and $\mathrm{Ti}-16 \mathrm{Nb}$ were $785 \pm 5^{\circ} \mathrm{C}, 740 \pm$ $5^{\circ} \mathrm{C}$ and $690 \pm 5^{\circ} \mathrm{C}$, respectively which are in agreement with the equilibrium binary phase diagram (figure 1). Small samples of size $20 \mathrm{~mm} \times 15 \mathrm{~mm} \times 3 \mathrm{~mm}$ were cut from the rolled alloys for solution treatment (ST) studies. The solution treatments consisted of a high temperature $(\beta \mathrm{ST})$ and low temperature $(\alpha+\beta \mathrm{ST})$ followed by water quenching (WQ) and furnace cooling (FC). The WQ specimens were aged at three different temperatures, viz. 350,450 and $550^{\circ} \mathrm{C}$ for $24 \mathrm{~h}$ and $\mathrm{AC}$.

\subsection{Microstructure and phase analysis}

The specimens for optical and scanning electron microscopy (OM and SEM) were prepared following standard metallographic techniques used for titanium and its alloys and etched with Kroll's reagent $\left(5 \mathrm{ml} \mathrm{HF}, 10 \mathrm{ml} \mathrm{HNO}_{3}\right.$ and $85 \mathrm{ml} \mathrm{H}_{2} \mathrm{O}$ ). The samples were examined in optical microscope in etched condition while in scanning electron microscopy (Leo 440i) in unetched condition in back scattered electron (BSE) mode. Transmission electron microscopy (TEM) of selected samples was carried out using Technaii 2020 transmission electron microscope. The X-ray diffraction (XRD) studies of bulk samples were performed using a Philips 3020 diffractometer with $\mathrm{CuK} \alpha$ radiation. The lattice parameters of the constituent phases in as-cast, hot-rolled and heat-treated specimens were calculated using standard programme Celn (Lagaree 1989-1993). The error in lattice parameters is shown in parenthesis. The electron probe microanalyser (EPMA) was employed to obtain chemical profile of the alloying elements (model: SX100, Ms Cameca). The spectral resolution was around $0.2 \mu \mathrm{m}$.

\section{Results and discussion}

In this $\S$, the microstructures and corresponding XRD results of as-cast, hot-rolled and heat-treated specimens will be discussed in detail. The results will be presented following the above sequence.

\subsection{As-cast alloys}

The optical microstructures of all the alloys reveal prior $\beta$ grains having very fine mixture of two phases (figure 2). The $\mathrm{Ti}-12 \mathrm{Nb}$, in addition also reveals the presence of subgrain boundaries. All the alloys display a typical transformed microstructure. The Ti-8Nb alloy reveals the presence of $\alpha$ and $\beta$ phases while the alloy $\mathrm{Ti}-12 \mathrm{Nb}$ shows $\alpha^{\prime \prime}$ (orthorhombic) and $\beta$ phases (figure 3). XRD pattern of the alloy Ti-16Nb displays the presence of $\alpha^{\prime}$ phase only (figure 3 ). In addition to this, it also exhibits the presence of strong solidification texture in the cast 

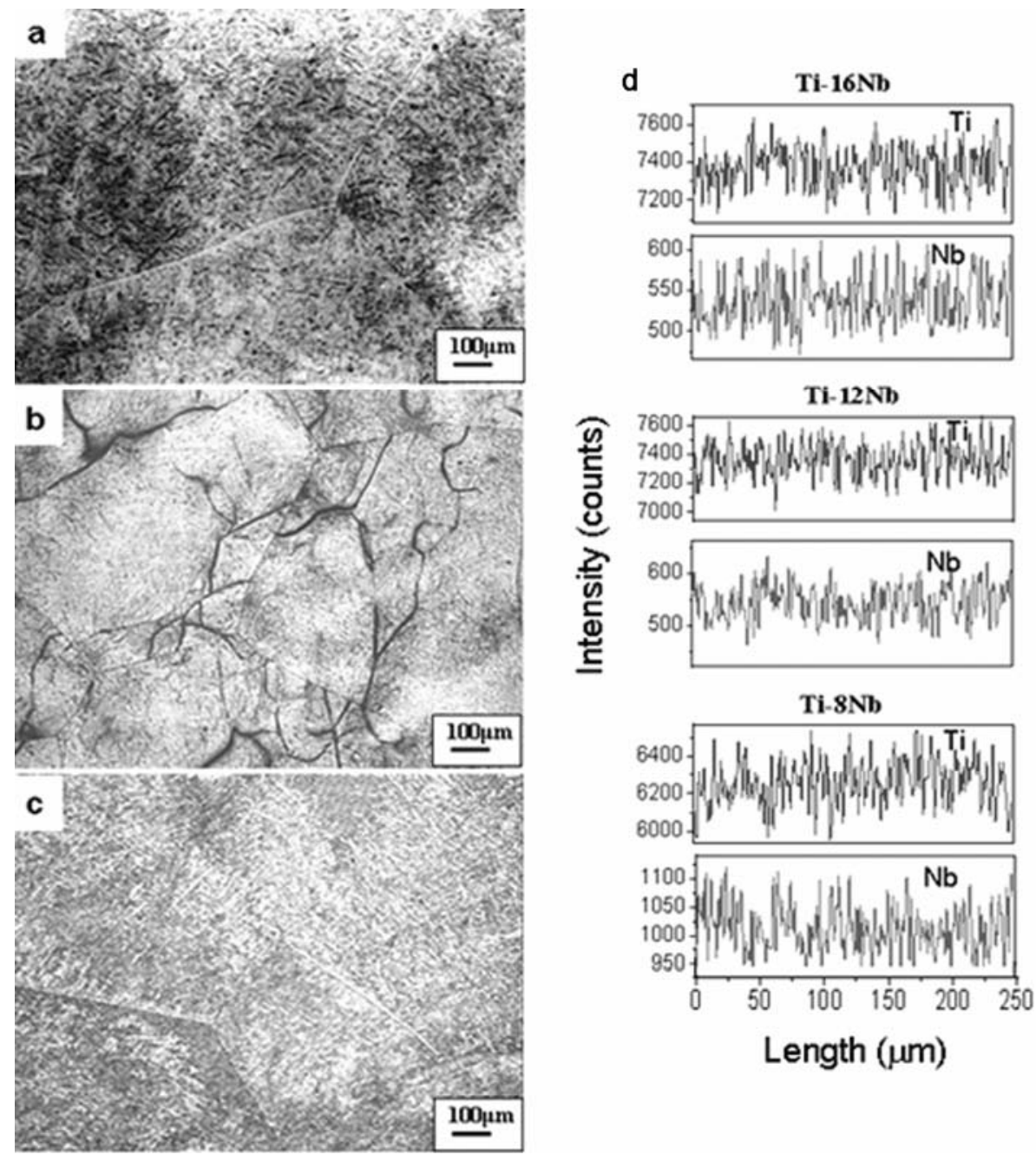

Figure 2. Optical microstructures of as-cast alloys: (a) $\mathrm{Ti}-8 \mathrm{Nb},(\mathbf{b}) \mathrm{Ti}-12 \mathrm{Nb}$, (c) $\mathrm{Ti}-16 \mathrm{Nb}$ and (d) elemental profile of $\mathrm{Ti}$ and $\mathrm{Nb}$.

Table 2. Phases observed by XRD and their lattice constants in experimental alloys in as-cast condition.

\begin{tabular}{lcccc}
\hline & & \multicolumn{3}{c}{ Lattice constant $(\AA)$} \\
\cline { 3 - 5 } Alloy & Phase(s) & $a$ & $b$ & $c$ \\
\hline Ti-8Nb & $\alpha$ & $2 \cdot 944(6)$ & - & $4 \cdot 672(6)$ \\
& $\beta$ & $3 \cdot 261(3)$ & - & - \\
Ti-12Nb & $\alpha^{\prime}$ & $3 \cdot 048(4)$ & $5 \cdot 082(6)$ & $4 \cdot 639(0)$ \\
& $\beta$ & $3 \cdot 255(6)$ & - & - \\
Ti-16Nb & $\alpha^{\prime}$ & $3 \cdot 170(1)$ & $5 \cdot 036(0)$ & $4 \cdot 643(4)$ \\
\hline
\end{tabular}

material which can be seen from the strong (310) reflection of the $\alpha^{\prime \prime}$ phase. As a result, $\beta$ phase peaks are getting masked in XRD pattern although the BSE microstructure (not shown) reveals the presence of two phases. The lattice parameters of the corresponding phases are shown in table 2 .
Based on the microstructures of the as-cast alloys and XRD patterns, it appears that the alloys first solidify in the single $\beta$ phase field. The alloy Ti $-8 \mathrm{Nb}$ then passes to the $\alpha+\beta$ phase field due to solid-state phase transformation, which is stable until room temperature. In the case of alloys, $\mathrm{Ti}-12 \mathrm{Nb}$ and $\mathrm{Ti}-16 \mathrm{Nb}, \beta$ phase transforms to the $\alpha^{\prime \prime}+\beta$ phases which seem to be stable until room temperature. The extent of micro segregation is reasonably less (figure 1d) as compared to typical cast materials since these alloys pass through single phase field during solidification.

\subsection{Hot-rolled alloys}

The optical microstructures taken from rolling direction (RD) plane of the hot-rolled specimens demonstrate typical features of rolled microstructures (figure 4). They exhibit elongated prior $\beta$ grain boundaries consisting of a fine distribution of the constituent phases. The alloy 
Ti-8Nb shows an unrecrystallized microstructure while the alloys $\mathrm{Ti}-12 \mathrm{Nb}$ and $\mathrm{Ti}-16 \mathrm{Nb}$ consist of unrecrystallized and recrystallized regions. The volume fractions of recrystallized grains of $\mathrm{Ti}-12 \mathrm{Nb}$ and $\mathrm{Ti}-16 \mathrm{Nb}$ in hotrolled condition are $22 \%$ and $53 \%$, respectively. The extent of recrystallization increases with increase in $\mathrm{Nb}$ content. This can be attributed to the high concentration of $\mathrm{Nb}$, which decreases the $\beta$ transus temperature. As a result, high $\mathrm{Nb}$ containing alloys get superheated during hot rolling since the gap between rolling temperature and $\beta$ transus temperature increases and thereby the alloy Ti$16 \mathrm{Nb}$ exhibits the highest volume fraction of recrystallized grains. XRD studies confirm the presence of two phases, $\alpha$ and $\beta$, in Ti-8Nb and $\alpha^{\prime \prime}$ and $\beta$ in Ti-12Nb and $\mathrm{Ti}-16 \mathrm{Nb}$ alloys (figure 5 ). The lattice parameters corresponding to these phases are given in table 3. TEM study of the hot-rolled $\mathrm{Ti}-16 \mathrm{Nb}$ alloy displays fine structure (figure 6a). A composite selected area diffraction (SAD) pattern of $\beta$ and $\omega$ phases is shown in figure $6 \mathrm{~b}$.

It is to be noted that the $\alpha^{\prime \prime}$ phase has been observed in both the as-cast and hot-rolled conditions in $\mathrm{Ti}-12 \mathrm{Nb}$ and $\mathrm{Ti}-16 \mathrm{Nb}$. In general, the $\beta \rightarrow \alpha^{\prime \prime}$ is a martensitic transformation, which has been reported in titanium alloys after $\beta$ heat treatment and WQ (Brown et al 1964; Young et al 1974; Sugimoto et al 1980; Singh et al 1993; Geetha et al 2001, 2004). The influence of solute concentration on the kinetics of $\beta \rightarrow \alpha^{\prime \prime}$ transformation has been studied by Jepson et al (1970) on a series of Ti-Nb alloys. It has been shown that martensitic start transformation temperature $\left(M_{\mathrm{s}}\right)$ depends on the critical cooling rate $\left(r_{\mathrm{c}}\right)$, which decreases with increase in $\mathrm{Nb}$ concentration. The critical cooling rate, $r_{\mathrm{c}}$, for unalloyed $\mathrm{Ti}$ is $10^{2 \circ} \mathrm{C} / \mathrm{s}$ and it reduces to $0 \cdot 3^{\circ} \mathrm{C} / \mathrm{s}$ after addition of 15 atom $\% \mathrm{Nb}$ (Jepson et al 1970). The observation of $\alpha^{\prime \prime}$ phase in as-cast and hot-rolled condition of the present study in $\mathrm{Ti}-12 \mathrm{Nb}$ and $\mathrm{Ti}-16 \mathrm{Nb}$ alloys can, therefore, be attributed to high $\mathrm{Nb}$ content which reduces critical cooling rate of $\beta \rightarrow \alpha^{\prime \prime}$ transformation.

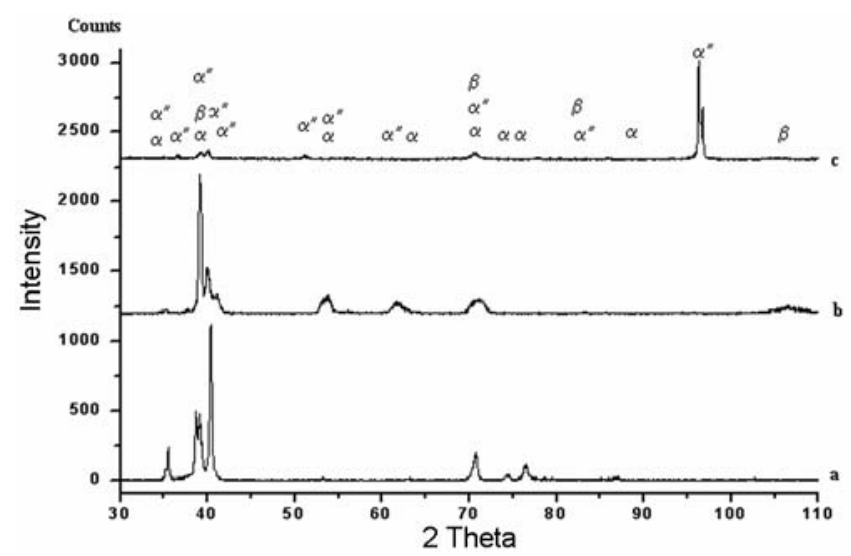

Figure 3. XRD patterns of as-cast alloys: (a) $\mathrm{Ti}-8 \mathrm{Nb}$, (b) $\mathrm{Ti}-12 \mathrm{Nb}$ and (c) Ti-16Nb.

\subsection{Microstructural features of heat-treated alloys}

3.3a $\beta$ heat treatments: All the alloys in the hot-rolled condition were heat treated above the $\beta$ transus temperature at $950^{\circ} \mathrm{C}$ for $30 \mathrm{~min}(\beta \mathrm{ST})$ and cooled at different rates (WQ and FC). This treatment results in various phases depending on alloy composition and cooling rates. The details of heat treatments and phases evolved during cooling are given in table 4.
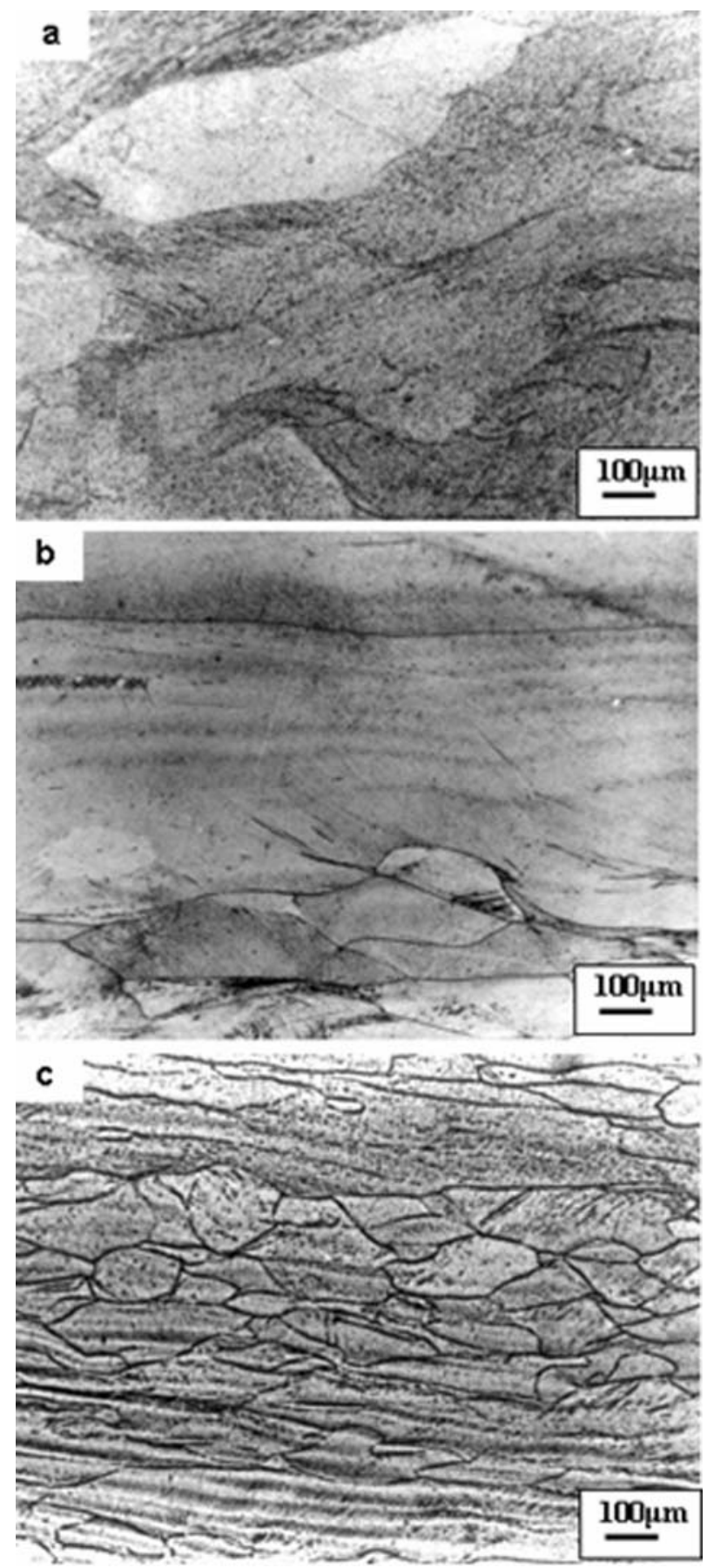

Figure 4. Optical microstructures of $80 \%$ hot-rolled alloys: (a) $\mathrm{Ti}-8 \mathrm{Nb},(\mathbf{b}) \mathrm{Ti}-12 \mathrm{Nb}$ and (c) $\mathrm{Ti}-16 \mathrm{Nb}$. 
The BSE microstructures of the alloys in the $\beta$ ST condition are shown in figure 7 . The WQ specimens exhibit a typical martensitic microstructure. Very fine platelet-type features indicative of martensitic transformation are seen inside the prior $\beta$ grains. The bright field (BF) TEM micrograph also reveals the presence of $\alpha^{\prime \prime}$ phase with platelet-type features (figure 8a). The corresponding SAD pattern of the $\alpha^{\prime \prime}$ phase is shown in figure $8 \mathrm{~b}$. The size of martensitic platelets decreases with increase in $\mathrm{Nb}$ content which is in agreement with that of martensitic microstructures of Ti-Mo alloys wherein the martensitic plates become finer with increase in Mo content (Davis et al 1979).

The XRD studies show the presence of $\alpha^{\prime \prime}$ (orthorhombic) in alloy Ti-8 $\mathrm{Nb}$ and $\alpha^{\prime \prime}$ and $\omega$ phases in alloys Ti$12 \mathrm{Nb}$ and $\mathrm{Ti}-16 \mathrm{Nb}$ (figure 9). Based on the X-ray peak intensities of $\alpha^{\prime \prime}$ and $\omega$ phases, it can be inferred that the volume fraction of $\omega$ is quite small as compared to that of $\alpha$ " phase and it increases with the increase in $\mathrm{Nb}$ content. The lattice parameters of the constituent phases in all alloys in the $\beta$ STWQ conditions are given in table 5. A comparison of the lattice parameters of $\alpha^{\prime \prime}$ phase indicates that the $b / a$ ratio decreases with increase in $\mathrm{Nb}$ concentration, while the $c$ parameter remains nearly constant. The observed change in the $b / a$ ratio is in agreement with

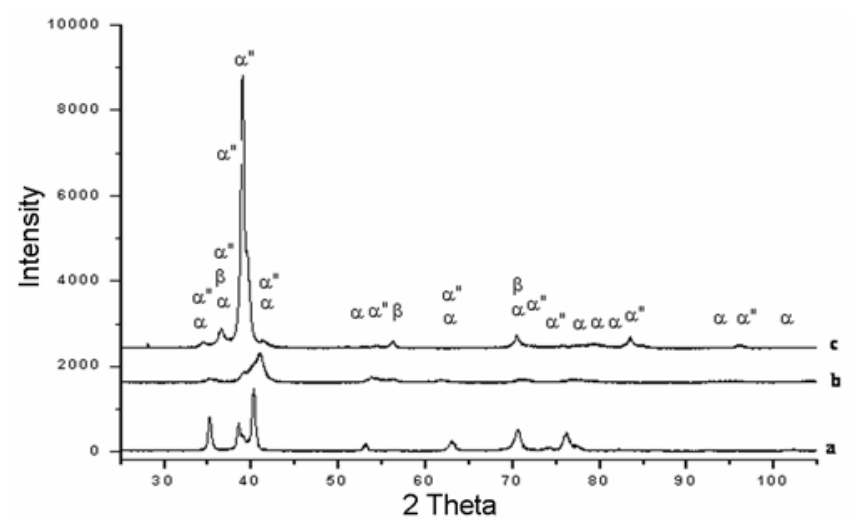

Figure 5. XRD patterns of hot-rolled alloys: (a) $\mathrm{Ti}-8 \mathrm{Nb}$, (b) $\mathrm{Ti}-12 \mathrm{Nb}$ and (c) $\mathrm{Ti}-16 \mathrm{Nb}$.

Table 3. Phases observed by XRD and their lattice constants in experimental alloys in $80 \%$ hot-rolled specimens.

\begin{tabular}{lcccc}
\hline & & \multicolumn{3}{c}{ Lattice constant $(\AA)$} \\
\cline { 3 - 5 } Alloy & Phase(s) & $a$ & $b$ & $c$ \\
\hline Ti-8Nb & $\alpha$ & $2 \cdot 953(5)$ & - & $4 \cdot 686(5)$ \\
& $\beta$ & $3 \cdot 262(0)$ & - & - \\
Ti-12Nb & $\alpha^{\prime \prime}$ & $3 \cdot 054(8)$ & $5 \cdot 085(4)$ & $4 \cdot 616(6)$ \\
& $\beta$ & $3 \cdot 264(0)$ & - & - \\
Ti-16Nb & $\alpha^{\prime \prime}$ & $3 \cdot 170(5)$ & $4 \cdot 969(2)$ & $4 \cdot 628(9)$ \\
& $\beta$ & $3 \cdot 268(0)$ & - & - \\
\hline
\end{tabular}

the results obtained by Brown et al (1964). The cla ratio of the $\omega$ phase in alloys $\mathrm{Ti}-12 \mathrm{Nb}$ and $\mathrm{Ti}-16 \mathrm{Nb}$ are 0.614 and $0 \cdot 612$, respectively. It has been suggested that $c / a$ ratio of this phase is always 0.613 , irrespective of the alloying additions (Hickman 1968, 1969a, b). The c/a ratios of the alloys in the present investigation are quite close to $0 \cdot 613$. The minor deviation of $c / a$ ratio from 0.613 observed in the present study can be attributed to the presence of a small volume fraction of the $\omega$ phase resulting in only a few non-overlapping peaks with very low intensities.

Two different types of martensitic structures i.e. $\alpha$ (hexagonal) and $\alpha^{\prime \prime}$ (orthorhombic) are reported in titanium alloys depending upon the content of $\beta$ alloying elements (Brown et al 1964; Young et al 1974; Sugimoto et al 1980; Collings 1984; Singh et al 1990; Boyer et al 1994; Geetha et al 2001, 2004). The critical composition limits of the $\beta$ alloying elements in binary Ti-X $(\mathrm{X}=\mathrm{Nb}$, Mo, Ta, W, etc) for the formation of $\alpha^{\prime \prime}$ have been reported in literature (Collings 1984; Boyer et al 1994). The $\alpha / \alpha^{\prime \prime}$ boundary in the binary Ti-Nb system is around 5.7 atom\%. The formation of the orthorhombic $\alpha^{\prime \prime}$ phase in the present investigation after $\beta$ ST WQ is therefore not surprising due to the presence of $\mathrm{Nb}$ contents which are higher than the critical limit. Banumathy et al (2009) recently studied the structure of $\alpha^{\prime \prime}$ phase using Rietveld refinement of XRD data of these alloys. They have shown that formation of $\alpha^{\prime \prime}$ phase occurs since $\mathrm{Ti} / \mathrm{Nb}$ atoms are not able to reach hexagonal positions during WQ. This breaks the hexagonal symmetry and results in formation of $\alpha^{\prime \prime}$ (orthorhombic) phase. It is to be noted that the space group of $\alpha^{\prime \prime}$ phase is a subgroup of both the $\alpha$ and $\beta$ phases.

As mentioned above, the alloys $\mathrm{Ti}-12 \mathrm{Nb}$ and $\mathrm{Ti}-16 \mathrm{Nb}$ exhibits the $\alpha^{\prime \prime}$ and $\omega$ phases in $\beta$ STWQ condition. The $\omega$ precipitation titanium alloys occurs in two distinct modes (Hickman 1968, 1969; Duerig et al 1980; Collings 1984). In relatively dilute alloy compositions, the $\omega$ phase forms during rapid quenching from the $\beta$ phase field to a temperature below the $\omega$ start temperature $\left(t_{\omega}\right)$. This is referred to as athermal $\omega$. The mechanism of the formation of athermal $\omega$ has been discussed earlier (Hickman 1968, 1969; Collings 1984). The $\omega$ phase also forms during aging of $\beta$-quenched alloys as well as in alloys richer in $\beta$ alloying elements. This is called isothermal $\omega$ (Hickman 1968, 1969; Duerig et al 1980; Collings 1984).

It has been reported that a narrow composition range exists with the overlapping boundary of the martensitic and $\beta+\omega$ phase field, in which $\omega$ appears athermally during rapid quenching from the $\beta$ phase field. Therefore, the presence of athermal $\omega$ phase in the $\beta$ STWQ condition in the present study indicates two possibilities. In the first case, the alloy forms three phases viz. $\alpha^{\prime \prime}, \beta$ and $\omega$ after quenching and it is difficult to detect small amount of $\beta$ phase by XRD technique due to low intensity and 


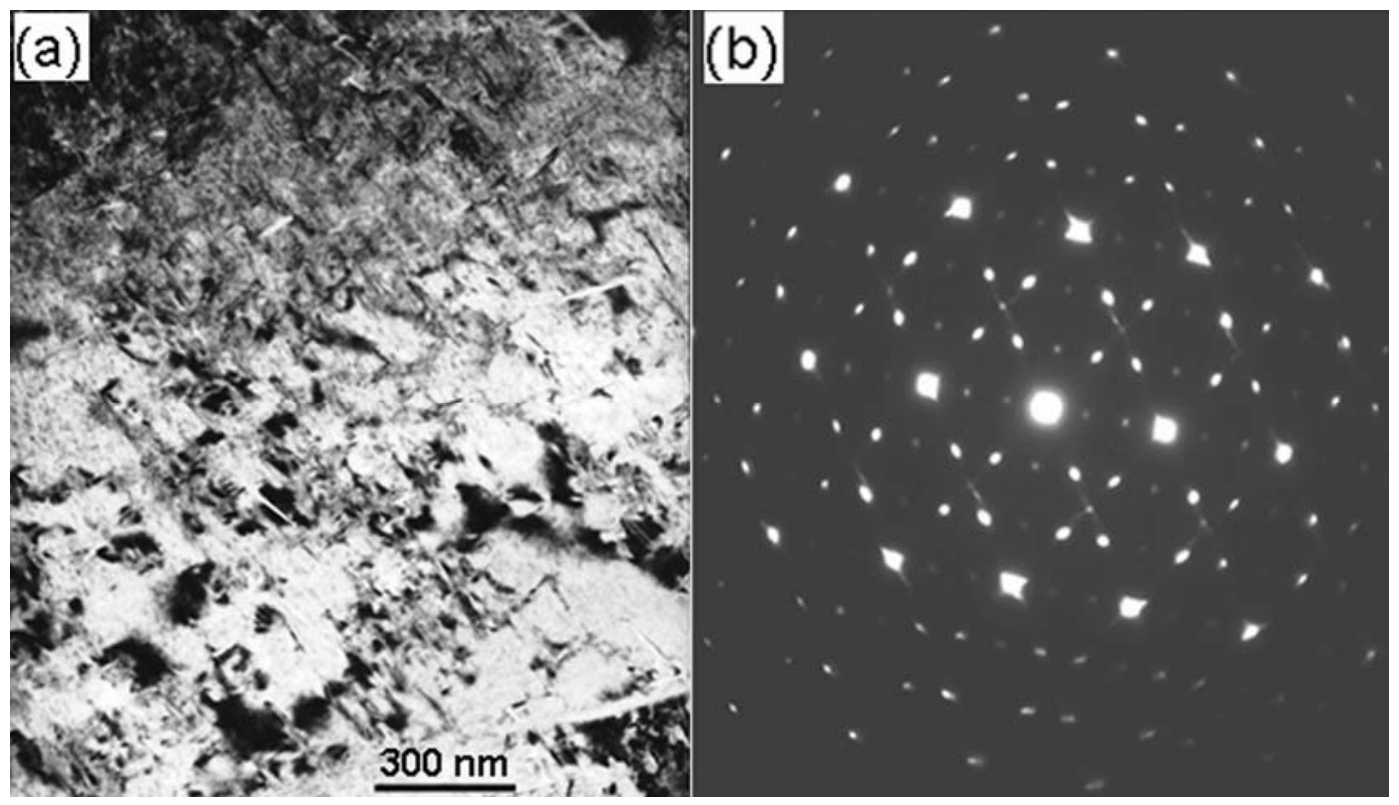

Figure 6. TEM microstructure of hot-rolled $\mathrm{Ti}-16 \mathrm{Nb}$ alloy: (a) $\mathrm{BF}$ and (b) diffraction pattern: [110] $\beta$ zone superimposed with [1120] $\omega$ and $[2110] \omega$ zones.

Table 4. $\beta$ and $\alpha+\beta$ heat treatment details for the experimental alloys.

\begin{tabular}{|c|c|c|c|c|c|}
\hline \multirow[b]{2}{*}{ Sl. No } & \multirow[b]{2}{*}{ Heat treatment } & \multirow[b]{2}{*}{ Designation } & \multicolumn{3}{|c|}{ Observed phases by XRD } \\
\hline & & & $\mathrm{Ti}-8 \mathrm{Nb}$ & $\mathrm{Ti}-12 \mathrm{Nb}$ & $\mathrm{Ti}-16 \mathrm{Nb}$ \\
\hline 1 & $950^{\circ} \mathrm{C}, 30 \mathrm{~min}+\mathrm{WQ}$ & $\beta$ STWQ & $\alpha^{\prime \prime}$ & $\alpha^{\prime}, \omega$ & $\alpha^{\prime}, \omega$ \\
\hline 2 & $\beta \mathrm{STWQ}+350^{\circ} \mathrm{C} / 24 \mathrm{~h}+\mathrm{AC}$ & $\beta$ STWQ A1 & $\alpha$ & $\alpha, \alpha^{\prime \prime}, \beta, \omega$ & $\alpha^{\prime}, \beta, \omega$ \\
\hline 3 & $\beta \mathrm{STWQ}+450^{\circ} \mathrm{C} / 24 \mathrm{~h}+\mathrm{AC}$ & $\beta$ STWQ A2 & $\alpha, \beta$ & $\alpha, \alpha^{\prime}, \beta, \omega$ & $\alpha, \alpha^{\prime}, \beta, \omega$ \\
\hline 4 & $\beta \mathrm{STWQ}+550^{\circ} \mathrm{C} / 24 \mathrm{~h}+\mathrm{AC}$ & $\beta$ STWQ A3 & $\alpha, \beta$ & $\alpha, \beta$ & $\alpha, \beta$ \\
\hline 5 & $950^{\circ} \mathrm{C}, 30 \mathrm{~min}+\mathrm{FC}$ & $\beta$ STFC & $\alpha, \beta, \omega$ & $\alpha, \beta, \omega$ & $\alpha, \beta, \omega$ \\
\hline 6 & $680^{\circ} \mathrm{C}, 1 \mathrm{~h}+\mathrm{WQ}$ & $\alpha+\beta$ STWQ & $\alpha, \beta, \omega$ & $\alpha, \alpha^{\prime \prime}, \beta, \omega$ & $\alpha, \alpha^{\prime}, \beta, \omega$ \\
\hline 7 & $\alpha+\beta \mathrm{STWQ}+350^{\circ} \mathrm{C} / 24 \mathrm{~h}+\mathrm{AC}$ & $\alpha+\beta$ STWQ A1 & $\alpha, \beta, \omega$ & $\alpha, \beta, \omega$ & $\alpha, \beta, \omega$ \\
\hline 8 & $\alpha+\beta \mathrm{STWQ}+450^{\circ} \mathrm{C} / 24 \mathrm{~h}+\mathrm{AC}$ & $\alpha+\beta$ STWQ A2 & $\alpha, \beta$ & $\alpha, \beta$ & $\alpha, \beta$ \\
\hline 9 & $\alpha+\beta \mathrm{STWQ}+550^{\circ} \mathrm{C} / 24 \mathrm{~h}+\mathrm{AC}$ & $\alpha+\beta$ STWQ A3 & $\alpha, \beta$ & $\alpha, \beta$ & $\alpha, \beta$ \\
\hline 10 & $680,1 \mathrm{~h}+\mathrm{FC}$ & $\alpha+\beta$ STFC & $\alpha, \beta, \omega$ & $\alpha, \beta, \omega$ & $\alpha, \beta, \omega$ \\
\hline
\end{tabular}

overlapping peaks. It is important to mention here that the first non-overlapping peak of the $\beta$ phase lies at $2 \theta$ equal to $55.54^{\circ}$ corresponding to $\{200\}$ reflection which is very close to $\{20 \overline{2} 1\}$ peak of $\omega$ phase. In the other case, the alloy consists of two different regions i.e. $\mathrm{Nb}$ lean and $\mathrm{Nb}$ rich due to micro segregation. Figure $7 \mathrm{~d}$ indicates the presence of micro segregation in $\mathrm{Ti}-12 \mathrm{Nb}$ and $\mathrm{Ti}-16 \mathrm{Nb}$ alloys. The $\mathrm{Nb}$ lean regions transform to $\alpha^{\prime \prime}$ martensitic phase while $\mathrm{Nb}$ rich regions probably go down into narrow composition range as mentioned above and it transforms to $\omega$ phase after quenching.

Moffat and Larbalestier (1988) studied the competition between the martensitic and $\omega$ phases in alloys 20-70 atom $\% \mathrm{Nb}$ as a function of quench rate and alloy composition. They have observed that as the temperature of $\beta$ phase alloys decreases, the instability of $b c c$ lattice increases. The $\alpha^{\prime \prime}$ and $\omega$ phases compete to form in a suf- ficiently unstable lattice. The mode of $\beta$ phase decomposition is determined by quench rate. The formation of $\alpha^{\prime \prime}$ phase is favoured by fast quenching rate in alloys of 25 atom\% $\mathrm{Nb}$ or less. The $\alpha^{\prime \prime}$ phase is not observed in alloys with high $\mathrm{Nb}$ contents. The $\omega$ phase is preferred by slow quench rate. High $\mathrm{Nb}(60-70$ atom\%) stabilizes a single $\beta$ phase microstructure.

It has been argued that both the $\beta \rightarrow \alpha^{\prime \prime}$ and $\beta \rightarrow \omega$ transformation are thermodynamically allowed over a wide range of alloy compositions (Moffat and Larbalestier 1988). It shows that the favoured transformation is determined by kinetics. The quench rate also determines the extent of diffusion possible during a quench, which may alter the athermal nature of $\beta \rightarrow \omega$ transformation. Moffat and Larbalestier (1988) observed both the $\alpha^{\prime \prime}$ and $\omega$ phases in 25 atom $\% \mathrm{Nb}$ alloy and attributed this to the fast quench rate at the perimeter of the specimen resulting 


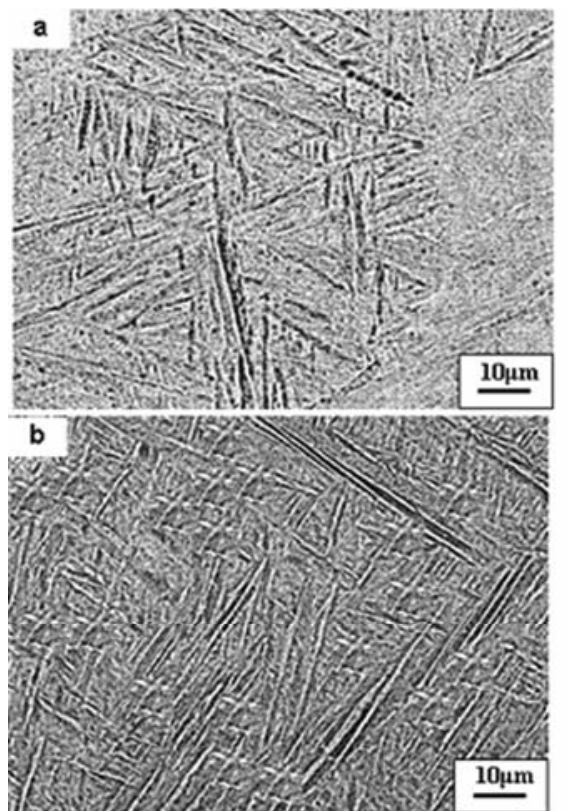

d
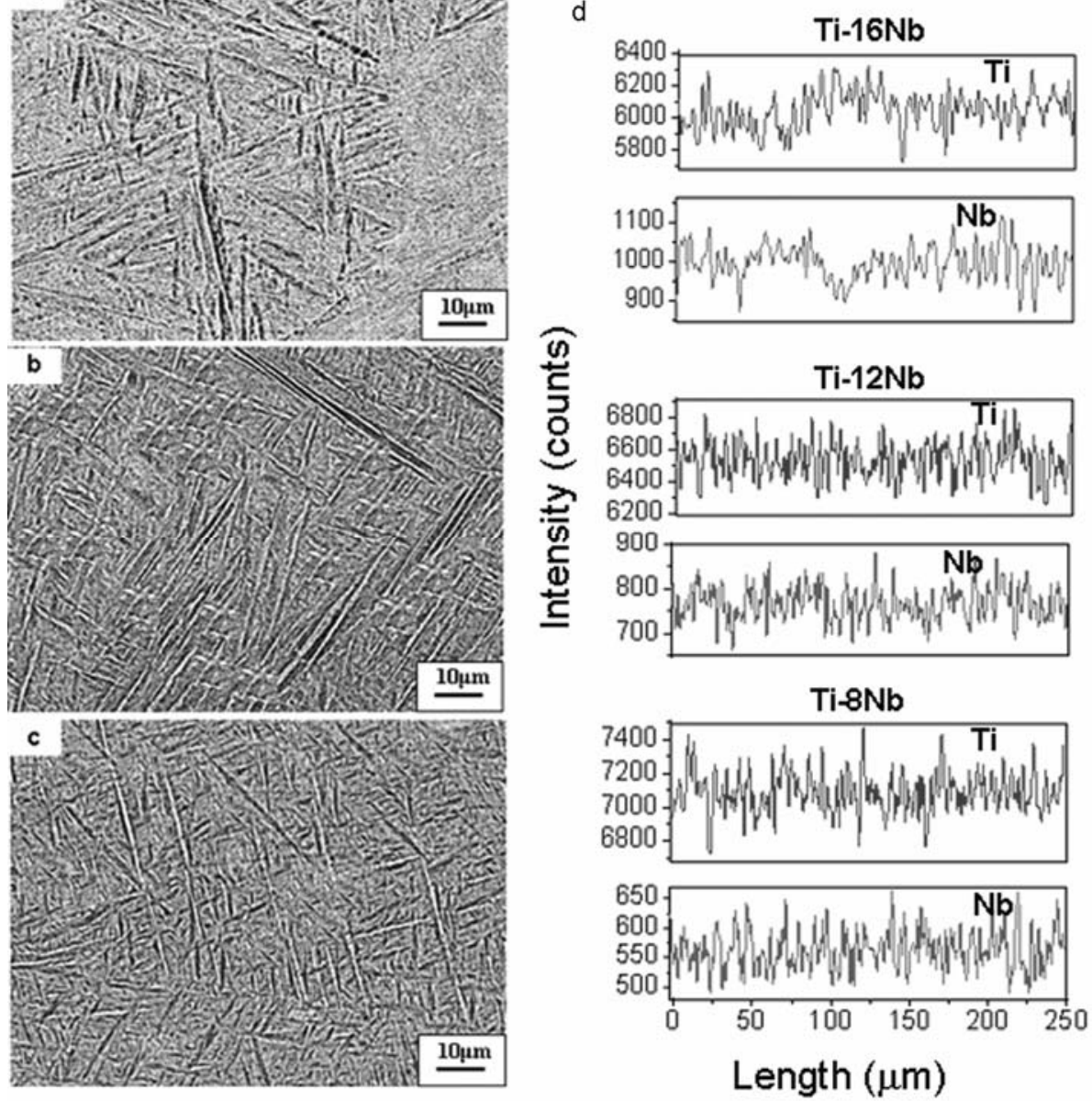

Figure 7. BSE microstructures of $\beta$ solution treated $\left(950^{\circ} \mathrm{C}, 30 \mathrm{~min}\right.$ and $\left.\mathrm{WQ}\right)$ alloys: (a) $\mathrm{Ti}-8 \mathrm{Nb},(\mathbf{b}) \mathrm{Ti}-12 \mathrm{Nb}(\mathbf{c}) \mathrm{Ti}-16 \mathrm{Nb}$ and (d) elemental profile of $\mathrm{Ti}$ and $\mathrm{Nb}$.
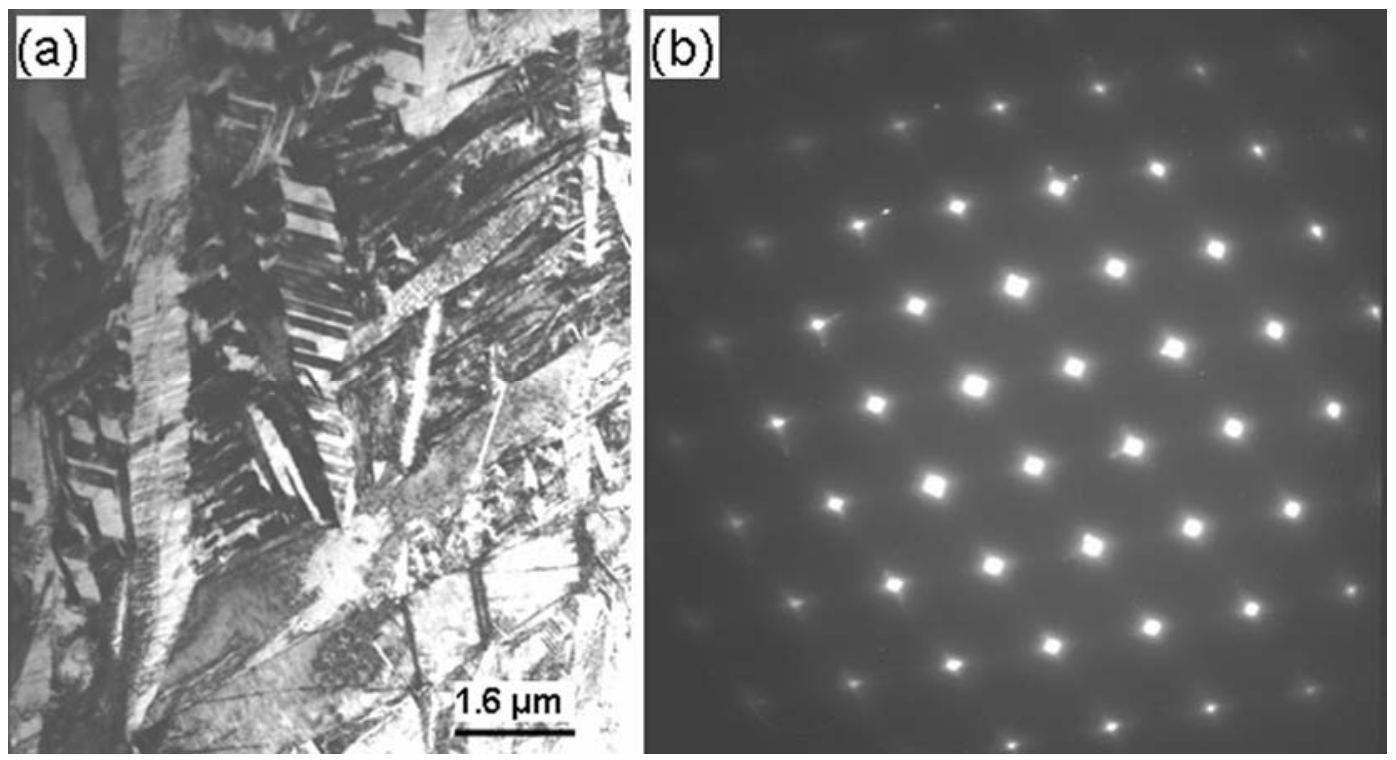

Figure 8. TEM microstructure of alloy Ti-16Nb in $\beta$ STWQ condition: (a) BF and (b) SAD pattern of $\alpha^{\prime \prime}$ phase with [002] zone axes. 
Table 5. Lattice constants of constituent phases in $\beta$ heat-treated alloys.

\begin{tabular}{|c|c|c|c|c|c|c|c|c|c|c|}
\hline \multirow[b]{2}{*}{ HT } & \multirow[b]{2}{*}{ Phase(s) } & \multicolumn{3}{|c|}{ Ti-8Nb alloy $(\AA)$} & \multicolumn{3}{|c|}{ Ti-12Nb alloy $(\AA)$} & \multicolumn{3}{|c|}{ Ti-16Nb alloy $(\AA)$} \\
\hline & & $a$ & $b$ & $c$ & $a$ & $b$ & $c$ & $a$ & $b$ & $c$ \\
\hline \multirow[t]{2}{*}{$\beta$ STWQ } & $\alpha^{\prime \prime}$ & $2 \cdot 980(0)$ & $5 \cdot 0762(5)$ & $4 \cdot 694(9)$ & $3 \cdot 059(0)$ & $5 \cdot 087(0)$ & $4 \cdot 703(0)$ & $3 \cdot 107(0)$ & $5 \cdot 014(0)$ & $4 \cdot 696(0)$ \\
\hline & $\omega$ & - & - & - & $4 \cdot 613(9)$ & - & $2 \cdot 834(1)$ & $4 \cdot 614(5)$ & - & $2 \cdot 826(1)$ \\
\hline \multirow[t]{3}{*}{$\beta$ STFC } & $\alpha$ & $2 \cdot 948(1)$ & - & $4 \cdot 684(3)$ & $2 \cdot 950(1)$ & - & $4 \cdot 683(8)$ & $2 \cdot 949(0)$ & & $4 \cdot 685(2)$ \\
\hline & $\beta$ & $3 \cdot 278(5)$ & - & - & $3 \cdot 279(6)$ & - & - & $3 \cdot 284(3)$ & - & - \\
\hline & $\omega$ & $4 \cdot 613(2)$ & - & $2 \cdot 816(0)$ & $4 \cdot 615(3)$ & - & $2 \cdot 813(8)$ & $4 \cdot 608(1)$ & - & $2 \cdot 826(6)$ \\
\hline \multirow[t]{4}{*}{$\beta \mathrm{STWQ}+\mathrm{A} 1$} & $\alpha^{\prime \prime}$ & - & - & - & $3 \cdot 054(2)$ & $5 \cdot 054(0)$ & $4 \cdot 711(9)$ & $3 \cdot 099(4)$ & $4 \cdot 976(3)$ & $4 \cdot 709(4)$ \\
\hline & $\alpha$ & $2 \cdot 968(7)$ & - & $4 \cdot 695(4)$ & $2 \cdot 949(8)$ & - & $4 \cdot 681(4)$ & - & - & - \\
\hline & $\beta$ & - & - & - & $3 \cdot 273(3)$ & - & - & $3 \cdot 292(0)$ & - & - \\
\hline & $\omega$ & - & - & - & $4 \cdot 617(3)$ & - & $2 \cdot 834(8)$ & $4 \cdot 623(6)$ & - & $2 \cdot 818(9)$ \\
\hline \multirow[t]{4}{*}{$\beta \mathrm{STWQ}+\mathrm{A} 2$} & $\alpha^{\prime \prime}$ & - & - & - & $3 \cdot 054(1)$ & $5 \cdot 053(1)$ & $4 \cdot 700(6)$ & $3 \cdot 097(4)$ & $5 \cdot 012(7)$ & $4 \cdot 697(9)$ \\
\hline & $\alpha$ & $2 \cdot 966(5)$ & - & $4 \cdot 701(9)$ & $2 \cdot 952(6)$ & - & $4 \cdot 683(2)$ & $2 \cdot 956(5)$ & - & $4 \cdot 690(7)$ \\
\hline & $\beta$ & $3 \cdot 284(1)$ & - & - & $3 \cdot 282(5)$ & - & - & $3 \cdot 287(6)$ & - & - \\
\hline & $\omega$ & - & - & - & $4 \cdot 611(6)$ & - & $2 \cdot 836(8)$ & $4 \cdot 614(6)$ & - & $2 \cdot 831(1)$ \\
\hline \multirow[t]{2}{*}{$\beta \mathrm{STWQ}+\mathrm{A} 3$} & $\alpha$ & $2 \cdot 962(0)$ & - & $4 \cdot 704(4)$ & $2 \cdot 961(2)$ & - & $4 \cdot 691(6)$ & $2 \cdot 967(1)$ & - & $4 \cdot 690(8)$ \\
\hline & $\beta$ & $3 \cdot 296(9)$ & - & - & $3 \cdot 300(8)$ & - & - & $3 \cdot 295(5)$ & - & - \\
\hline
\end{tabular}

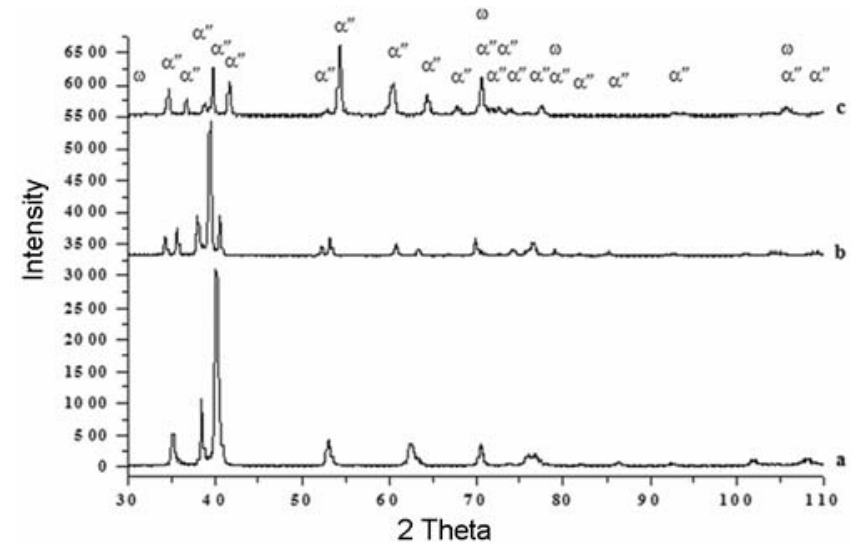

Figure 9. XRD patterns of $\beta$ solution treated $\left(950^{\circ} \mathrm{C}, 30 \mathrm{~min}\right.$ and WQ) alloys: (a) Ti-8Nb, (b) Ti-12Nb and (c) $\mathrm{Ti}-16 \mathrm{Nb}$.

in $\alpha^{\prime \prime}$ phase while at the centre, it was slow enough to facilitate the formation of $\omega$ precipitate.

The $\beta$ STFC specimens show a basket weave type microstructure (figure 10). The size of $\alpha$ platelets decreases with increase in $\mathrm{Nb}$ concentration. The $\mathrm{Ti}-16 \mathrm{Nb}$ alloy exhibits a cris-cross type of microstructure with fine plates. XRD studies reveal the presence of $\alpha, \beta$ and $\omega$ phases in all the three alloys (figure 11). The intensity of $\beta$ phase peaks increases with increase in $\mathrm{Nb}$ content. This indicates that the volume fraction of the $\beta$ phase increases since $\mathrm{Nb}$ is a $\beta$ stabilizer. The lattice parameters of the constituent phases in $\beta$ STFC condition are given in table 5. The lattice parameters of $\alpha$ phase remain nearly the same in all alloys while the lattice parameter of the $\beta$ phase increases with increase in $\mathrm{Nb}$ content. The $c / a$ ratio of $\omega$ phase remains very close to 0.613 as mentioned above (Hickman 1968, 1969; Davis et al 1979). The $\omega$ phase observed in the $\beta$ STFC condition is different than that of athermal $\omega$ seen in $\beta$ STWQ condition. It appears that the $\beta$ phase is getting enriched due to preferential partitioning of $\mathrm{Nb}$ during furnace cooling. The elemental profiles exhibit the presence of micro segregations of $\mathrm{Ti}$ and $\mathrm{Nb}$ atoms (figure $10 \mathrm{~d}$ ). This shifts the overall composition of the $\beta$ phase to $\omega+\beta$ phase field (Collings 1984; Boyer et al 1994) which results in $\omega$ and $\beta$ phases after furnace cooling.

3.3b $\alpha+\beta$ heat treatments: The details of $\alpha+\beta$ heat treatments and the corresponding observed phases are given in table 4 . It is to be noted that the solution treatment temperature $\left(680^{\circ} \mathrm{C}\right)$ lies within $\alpha+\beta$ phase field for both the alloys $\mathrm{Ti}-8 \mathrm{Nb}$ and $\mathrm{Ti}-12 \mathrm{Nb}$ while for the alloy $\mathrm{Ti}-16 \mathrm{Nb}$, it is very close to $\beta$ transus temperature. BSE micrographs of the $\alpha+\beta$ STWQ are given in figure 12 which reveal a very fine microstructure for all the three alloys. BSE microstructure of the alloy $\mathrm{Ti}-8 \mathrm{Nb}$ (figure 12a) exhibits $\alpha$ platelets $\left(\alpha_{\mathrm{p}}\right)$ in transformed $\beta$ regions. The alloy, Ti-12Nb, consists of very fine platelets while the alloy, Ti-16Nb, exhibits transformed $\beta$ with interior short and elongated $\alpha$. TEM BF micrograph of the alloy $\mathrm{Ti}-16 \mathrm{Nb}$ reveals fine microstructure (figure 13). The $\omega$ phase is finely distributed inside the $\alpha$ and $\alpha^{\prime \prime}$ plates.

The XRD studies of $\alpha+\beta$ STWQ specimens reveal the presence of $\alpha, \beta$ and $\omega$ phases in alloy Ti-8Nb and $\alpha, \alpha^{\prime \prime}$, $\beta$ and $\omega$ phases in both the alloys Ti-12Nb and Ti-16Nb (table 4). The lattice parameters of all the observed phases are given in table 6. It appears that during $\alpha+\beta$ heat treatment of the alloy $\mathrm{Ti}-8 \mathrm{Nb}, \alpha$ and $\beta$ phases are getting enriched by $\mathrm{Ti}$ and $\mathrm{Nb}$, respectively due to 


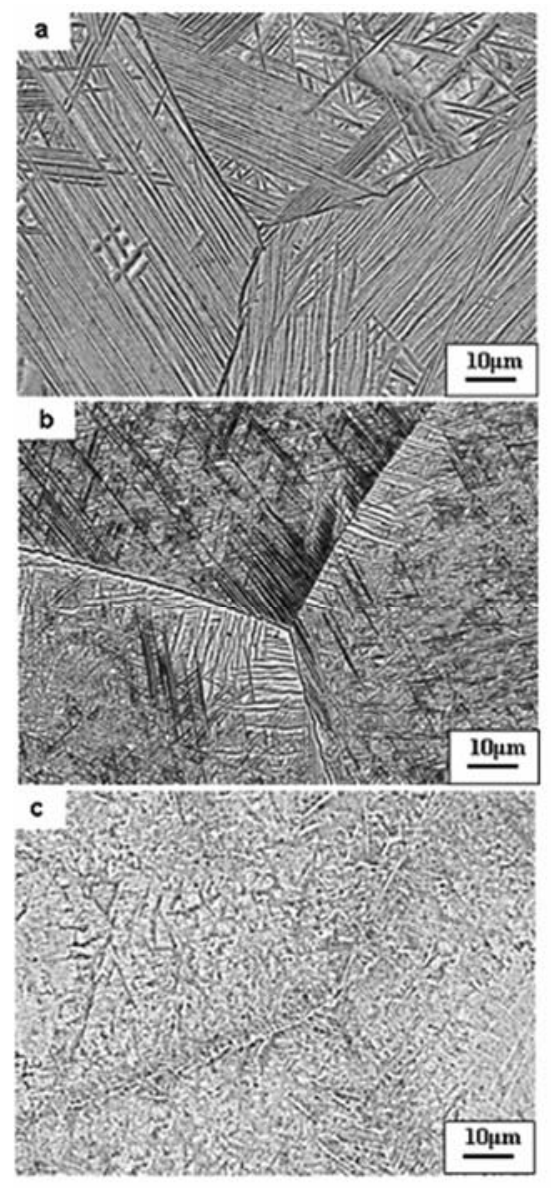

d

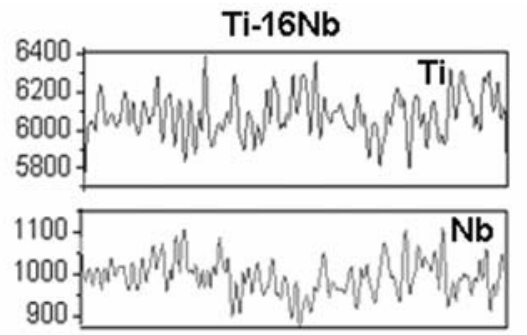

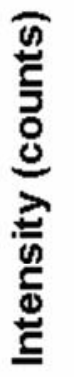
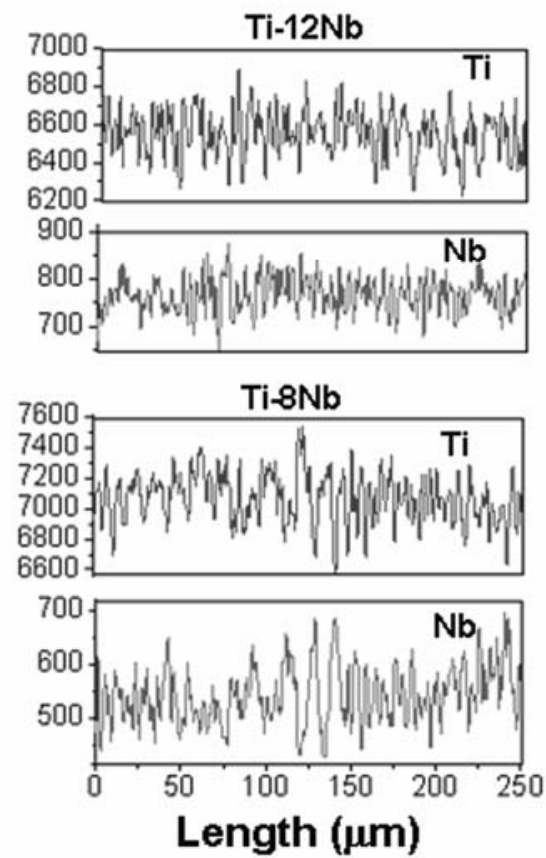

Figure 10. BSE microstructures of $\beta$ solution treated $\left(950^{\circ} \mathrm{C}, 30 \mathrm{~min}\right.$ and $\left.\mathrm{FC}\right)$ alloys: (a) $\mathrm{Ti}-8 \mathrm{Nb},(\mathbf{b}) \mathrm{Ti}-12 \mathrm{Nb},(\mathbf{c}) \mathrm{Ti}-16 \mathrm{Nb}$ and (d) elemental profile of $\mathrm{Ti}$ and $\mathrm{Nb}$.

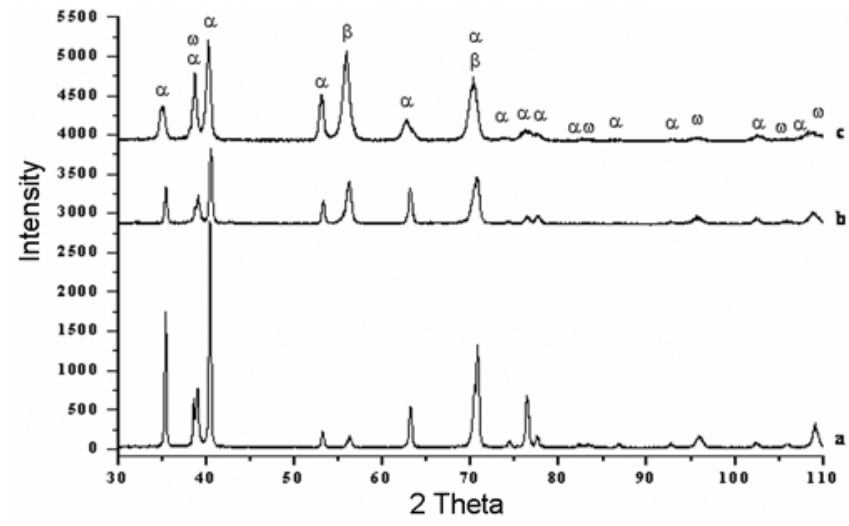

Figure 11. XRD patterns of $\beta$ solution treated $\left(950^{\circ} \mathrm{C}, 30 \mathrm{~min}\right.$ and FC) alloys: (a) Ti-8Nb, (b) Ti-12Nb and (c) Ti-16Nb.

partitioning effect (figure 12). As a result, it shifts the composition of $\mathrm{Nb}$ enriched phase to $\alpha^{\prime \prime}+\omega+\beta$ phase field (Collings 1984; Boyer et al 1994). The absence of $\alpha^{\prime \prime}$ phase in this specimen can, therefore, be probably attributed to the small volume fraction of $\alpha^{\prime \prime}$ phase, which cannot be detected by XRD due to low intensity and overlapping of peaks.

The evolution of the phases in alloys $\mathrm{Ti}-12 \mathrm{Nb}$ and $\mathrm{Ti}-$ $16 \mathrm{Nb}$ is similar to that of the alloy $\mathrm{Ti}-8 \mathrm{Nb}$. The increase in $\mathrm{Nb}$ content increases the volume fraction of $\beta$ phase in $\alpha+\beta$ phase field at $680^{\circ} \mathrm{C}$. In this case too, the alloy concentration lies in three-phase field i.e. $\alpha^{\prime \prime}+\beta+\omega$ as mentioned above (Collings 1984) thereby resulting in the formation of $\alpha, \alpha^{\prime \prime}, \beta$ and $\omega$ phases after the $\alpha+\beta$ STWQ heat treatment.

The microstructures of the experimental alloys in the $\alpha+\beta$ STFC condition are shown in figure 14 . The FC specimens reveal the presence of a two-phase microstructure although the morphologies of the phases in three alloys are quite different. A comparison of WQ and FC microstructures shows that the volume fraction of the $\alpha$ phase increases with decreasing cooling rates. The XRD studies of $\alpha+\beta$ STFC specimens reveal the presence of $\alpha, \beta$ and $\omega$ phases. The lattice parameters of these phases are given in table 6 . On slow cooling from $\alpha+\beta \mathrm{ST}$, there is an enrichment of phase in $\mathrm{Nb}$ (figure 14) which shifts the $\beta$ phase composition to $\omega+\beta$ phase field 

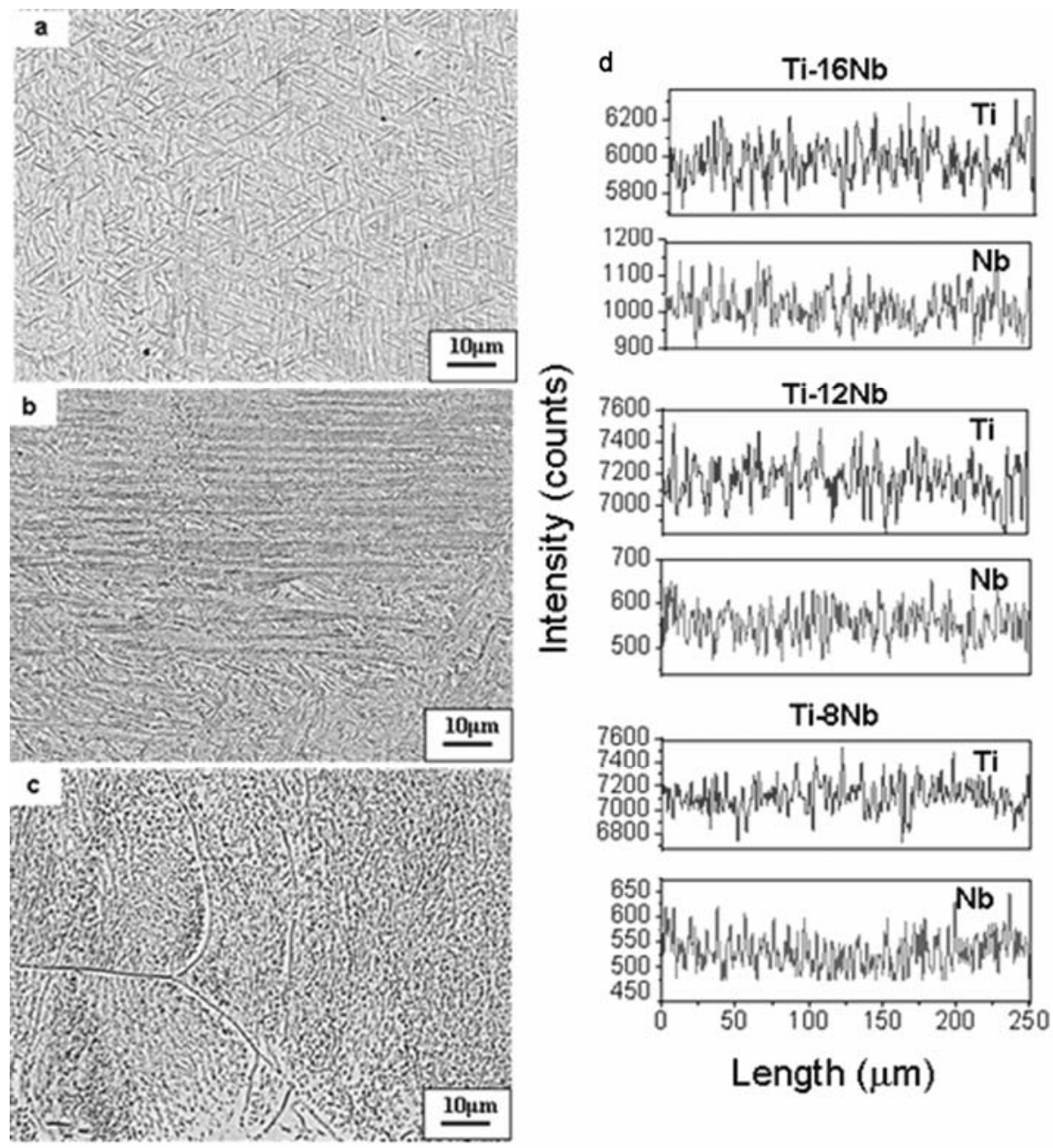

Figure 12. BSE microstructures of $\alpha+\beta$ solution treated $\left(680^{\circ} \mathrm{C}, 1 \mathrm{~h}\right.$ and WQ) alloys: (a) $\mathrm{Ti}-8 \mathrm{Nb},(\mathbf{b}) \mathrm{Ti}-12 \mathrm{Nb}$, (c) $\mathrm{Ti}-16 \mathrm{Nb}$ and (d) elemental profile of $\mathrm{Ti}$ and $\mathrm{Nb}$.

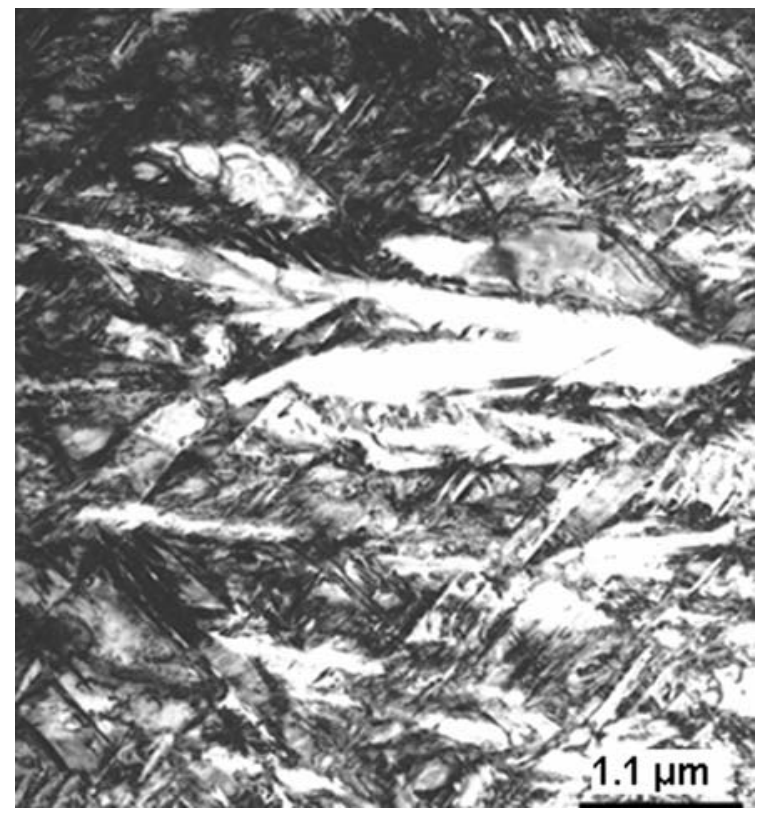

Figure 13. $\mathrm{BF}$ TEM micrograph of alloy $\mathrm{Ti}-16 \mathrm{Nb}$ in $\alpha+\beta$ STWQ condition.
(Collings 1984). As a result, $\alpha+\beta$ STFC heat treatment results in $\alpha, \beta$ and $\omega$ phases in all the three alloys.

\subsection{Aging treatments}

The aging treatments have been carried out at three different temperatures, viz. 350,450 and $550^{\circ} \mathrm{C}$ for solution treated and WQ specimens. All the samples have been air cooled after aging.

3.4a $\beta$ solution treatment: The $\beta$ WQ specimen shows a gradual change in the microstructure with increasing aging temperatures. The WQ specimen of the alloy $\mathrm{Ti}-$ $8 \mathrm{Nb}$ displays platelets of martensitic phase (figure 15). The aging at $350^{\circ} \mathrm{C}$ reduces the sharpness of the martensitic plates and also introduces a globular morphology. The aging at $450^{\circ} \mathrm{C}$ has clearly resulted in coarse $\alpha$ plates (figure 15). Further increase in aging temperature $\left(550^{\circ} \mathrm{C}\right)$ leads to the formation of thicker $\alpha$ plates. These $\alpha$ plates consist of fine parallel plates inside having newly nucleated $\alpha$ plates. 
Table 6. Lattice constants of constituent phases in $\alpha+\beta$ heat treated alloys.

\begin{tabular}{|c|c|c|c|c|c|c|c|c|c|c|}
\hline \multirow[b]{2}{*}{ HT } & \multirow[b]{2}{*}{ Phase } & \multicolumn{3}{|c|}{ Ti-8Nb alloy $(\AA)$} & \multicolumn{3}{|c|}{ Ti-12Nb alloy $(\AA)$} & \multicolumn{3}{|c|}{ Ti-16Nb alloy $(\AA)$} \\
\hline & & $a$ & $b$ & $c$ & $a$ & $b$ & $c$ & $a$ & $b$ & $c$ \\
\hline \multirow[t]{4}{*}{$(\alpha+\beta)$ STWQ } & $\alpha^{\prime \prime}$ & - & - & - & $3 \cdot 004(6)$ & $4.970(9)$ & $4 \cdot 748(1)$ & $3 \cdot 089(4)$ & $4 \cdot 904(8)$ & $4.692(0)$ \\
\hline & $\alpha$ & $2 \cdot 954(9)$ & - & $4 \cdot 692(9)$ & $2 \cdot 951(1)$ & - & $4 \cdot 689(3)$ & $2 \cdot 950(8)$ & - & $4 \cdot 655(6)$ \\
\hline & $\beta$ & $3 \cdot 275(6)$ & - & - & $3 \cdot 278(7)$ & - & - & $3 \cdot 282(7)$ & - & - \\
\hline & $\omega$ & $4 \cdot 614(2)$ & - & $2 \cdot 827(9)$ & $4 \cdot 620(5)$ & - & $2 \cdot 820(6)$ & $4 \cdot 586(0)$ & - & $2 \cdot 819(9)$ \\
\hline \multirow[t]{3}{*}{$(\alpha+\beta) \mathrm{STFC}$} & $\alpha$ & $2 \cdot 942(0)$ & - & $4 \cdot 674(8)$ & $2 \cdot 943(5)$ & - & $4 \cdot 683(0)$ & $2 \cdot 944(5)$ & - & $4 \cdot 685(6)$ \\
\hline & $\beta$ & $3 \cdot 270(9)$ & - & - & $3 \cdot 281(3)$ & - & - & $3 \cdot 286(8)$ & - & - \\
\hline & $\omega$ & $4 \cdot 599(9)$ & - & $2 \cdot 809(8)$ & $4 \cdot 590(1)$ & - & $2 \cdot 824(5)$ & $4 \cdot 624(8)$ & - & $2 \cdot 821(8)$ \\
\hline \multirow{3}{*}{$\begin{array}{l}(\alpha+\beta) \\
\quad \text { STWQ + A1 }\end{array}$} & $\alpha$ & $2 \cdot 952(4)$ & - & $4 \cdot 688(7)$ & $2 \cdot 958(6)$ & - & $4 \cdot 683(1)$ & $2 \cdot 957(7)$ & - & $4 \cdot 685(3)$ \\
\hline & $\beta$ & $3 \cdot 272(5)$ & - & - & $3 \cdot 274(2)$ & - & - & $3 \cdot 276(6)$ & - & - \\
\hline & $\omega$ & $4 \cdot 597(5)$ & - & $2 \cdot 825(1)$ & $4 \cdot 610(0)$ & - & $2 \cdot 816(1)$ & $4 \cdot 620(4)$ & - & $2 \cdot 822(4)$ \\
\hline \multirow{3}{*}{$\begin{array}{l}(\alpha+\beta) \\
\quad \text { STWQ + A2 }\end{array}$} & $\alpha$ & $2 \cdot 952(3)$ & - & $4 \cdot 691(0)$ & $2 \cdot 953(0)$ & - & $4 \cdot 692(9)$ & $2 \cdot 955(2)$ & - & $4 \cdot 694(3)$ \\
\hline & $\beta$ & $3 \cdot 274(4)$ & - & - & $3 \cdot 275(6)$ & - & - & $3 \cdot 278(7)$ & - & - \\
\hline & $\omega$ & - & - & - & - & - & - & $4 \cdot 626(5)$ & - & $2 \cdot 817(8)$ \\
\hline \multirow{3}{*}{$\begin{array}{l}(\alpha+\beta) \\
\quad \text { STWQ }+ \text { A3 }\end{array}$} & $\alpha$ & $2 \cdot 954(5)$ & - & $4 \cdot 686(9)$ & $2 \cdot 958(8)$ & - & $4 \cdot 685(2)$ & $2 \cdot 959(8)$ & - & $4 \cdot 666(7)$ \\
\hline & $\beta$ & $3 \cdot 277(3)$ & - & - & $3 \cdot 281(7)$ & - & - & $3 \cdot 287(3)$ & - & - \\
\hline & $\omega$ & - & - & - & - & - & - & $4 \cdot 629(3)$ & - & $2 \cdot 838(6)$ \\
\hline
\end{tabular}
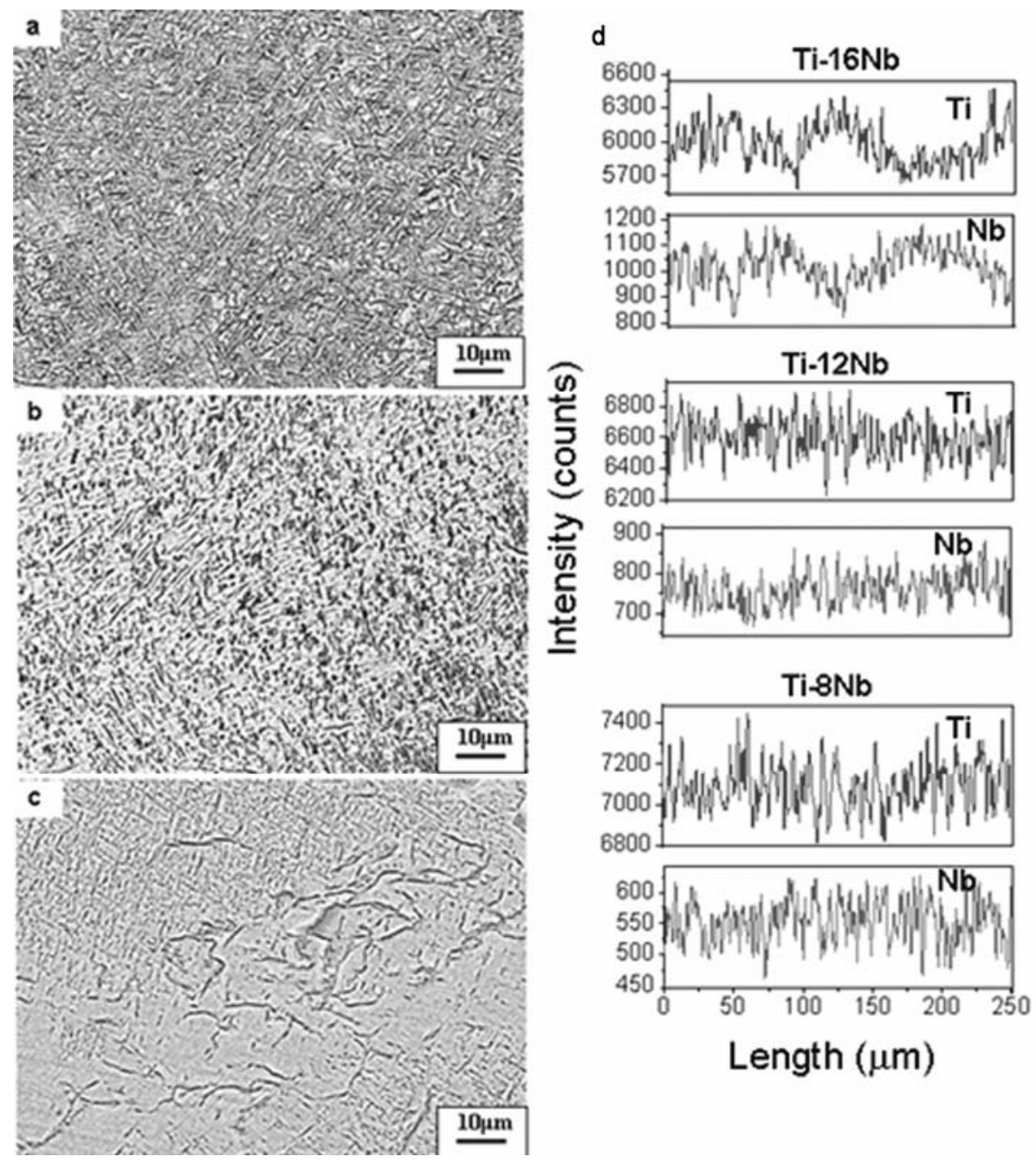

Figure 14. BSE SEM microstructures of $\alpha+\beta$ solution treated $\left(680^{\circ} \mathrm{C}, 1 \mathrm{~h}\right.$ and $\left.\mathrm{FC}\right)$ alloys: (a) $\mathrm{Ti}-8 \mathrm{Nb},(\mathbf{b}) \mathrm{Ti}-12 \mathrm{Nb}$, (c) $\mathrm{Ti}-16 \mathrm{Nb}$ and (d) elemental profile of $\mathrm{Ti}$ and $\mathrm{Nb}$. 
The alloy Ti-8Nb in $\beta$ STWQ condition consists of $\alpha^{\prime \prime}$ only. The aging of WQ specimen at $350^{\circ} \mathrm{C}$ results in $\alpha$ while aging at 450 and $550^{\circ} \mathrm{C}$ shows the presence of $\alpha$ and $\beta$ phases (table 4). The lattice parameters of the $\alpha$ phase of aged specimens are nearly the same while the lattice parameter of the $\beta$ phase slightly increases. It can be seen that $a$ and $c$ parameters of the aged specimens are higher than those of $\beta$ STFC specimen. This can be
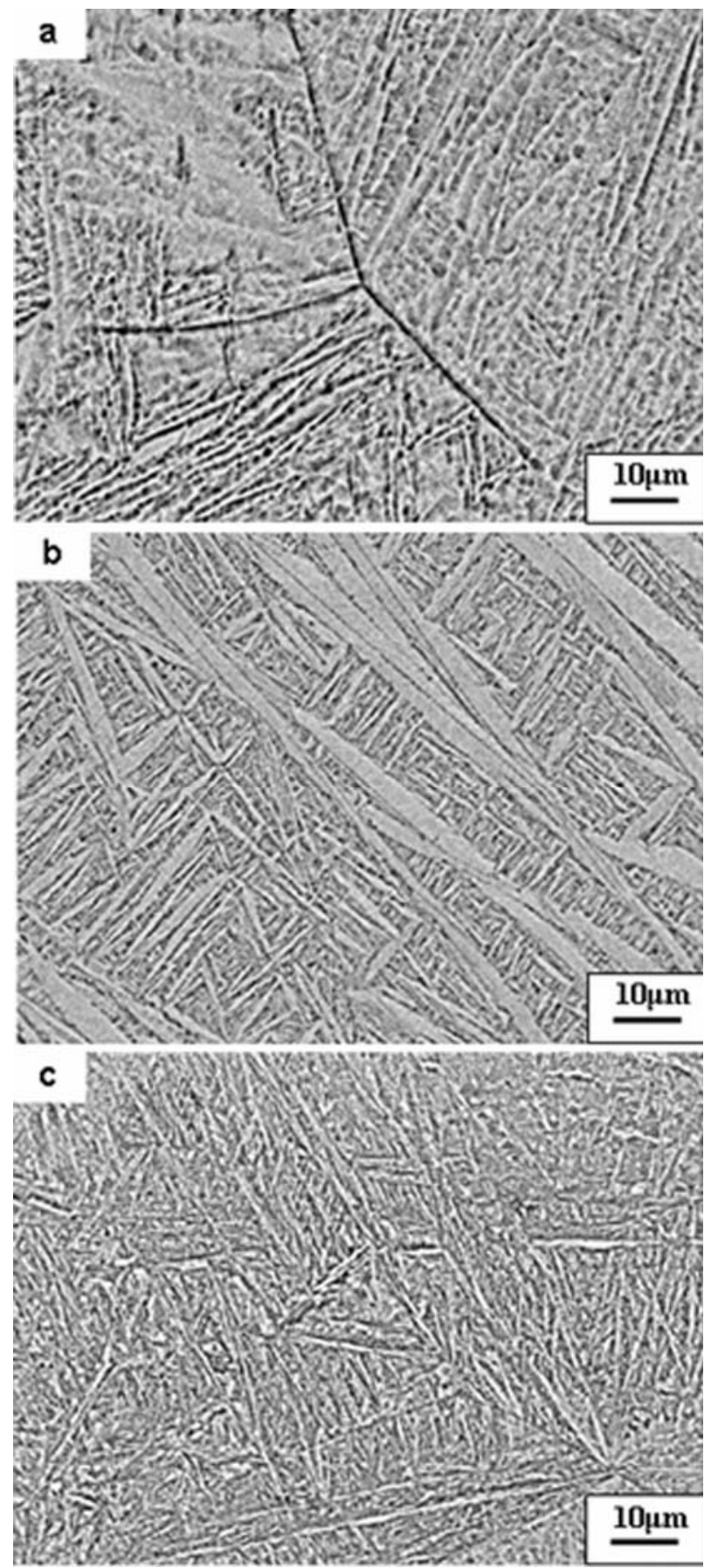

Figure 15. BSE SEM microstructures of $\beta$ solution treated $\left(950^{\circ} \mathrm{C}, 30 \mathrm{~min}\right.$ and WQ) and aged at $450^{\circ} \mathrm{C}, 24 \mathrm{~h}$ and $\mathrm{AC}$ (A2) alloys: (a) $\mathrm{Ti}-8 \mathrm{Nb}$, (b) $\mathrm{Ti}-12 \mathrm{Nb}$ and (c) $\mathrm{Ti}-16 \mathrm{Nb}$. attributed to a composition change of $\alpha$ phase in $\beta$ STFC specimens due to the presence of $\beta$ and $\omega$ phases.

The presence of $\alpha$ phase clearly indicates that $\alpha^{\prime \prime}$ martensitic phase has completely transformed to the $\alpha$ phase at $350^{\circ} \mathrm{C}$ aging. It is important to mention that orthorhombic martensitic $\alpha^{\prime \prime}$ phase can transform to $\alpha+\beta$ $\left(M_{\mathrm{s}}>\right.$ room temperature) or $\beta\left(M_{\mathrm{s}}=\right.$ room temperature $)$, where $M_{\mathrm{s}}$ is the martensitic start temperature (Murakami 1980). The presence of $\alpha$ phase in $350^{\circ} \mathrm{C}$ aged specimen indicates two possibilities: (i) transformation of $\alpha^{\prime \prime}$ to $\alpha$ phase and (ii) aging temperature is inappropriate for formation of enough $\beta$ phase to be detected by XRD technique.

A transformation of the $\alpha^{\prime \prime}$ to $\alpha$ phase without $\beta$ precipitation as observed in $350^{\circ} \mathrm{C}$ aged specimen has been reported (Young et al 1974). It has been observed that the $\alpha^{\prime \prime}$ phase transforms through precipitation of $\alpha$ needles rather than that of $\beta$ particles. Singh et al (1993) reported the transformation of $\alpha^{\prime \prime}$ to $\alpha$ by aging at a stabilizing treatment temperature $\left(530^{\circ} \mathrm{C}, 6 \mathrm{~h}\right)$ without any precipitation of $\beta$ phase. In the case of the alloy Ti- $8 \mathrm{Nb}$, it appears that $\alpha^{\prime \prime}$ phase transforms to $\alpha$ or $\alpha$ and $\beta$ phases during aging depending on aging temperatures.

Aging $\beta$ WQST of the alloy $\mathrm{Ti}-12 \mathrm{Nb}$ reduces the sharpness of the edge of $\alpha$ plates, increases the size, introduces globularization and exhibits newly nucleated $\alpha$ plates aligned parallel within the large $\alpha$ plates. The $550^{\circ} \mathrm{C}$ aged microstructure of the alloy $\mathrm{Ti}-12 \mathrm{Nb}$ exhibits platelet structure. The platelet structure is absent in alloy $\mathrm{Ti}-16 \mathrm{Nb}$ and aging has introduced fine microstructure.

The aging of $\beta$ STWQ specimens of the alloy Ti-12Nb results in $\alpha, \alpha^{\prime \prime}, \beta$ and $\omega$ phases at 350 and $450^{\circ} \mathrm{C}$ and $\alpha$ and $\beta$ phases at $550^{\circ} \mathrm{C}$ (table 4 ). The alloy Ti-16Nb consists of $\alpha^{\prime \prime}, \beta, \omega, \alpha^{\prime \prime}, \alpha, \beta, \omega, \alpha, \beta$ phases in 350,450 and $550^{\circ} \mathrm{C}$ aged specimens, respectively (table 4 ). The lattice parameters of the constituent phases are given in table 5. The lattice parameters of $\alpha^{\prime \prime}$ phases remain nearly constant in comparison to those of $\beta$ STWQ specimen. The lattice parameter of $\alpha$ and $\beta$ phases exhibits highest value in case of $550^{\circ} \mathrm{C}$ aged specimens as compared to those of $\beta$ STFC and other aged specimens. This can again be attributed to partitioning of alloying elements in $\alpha$ and $\beta$ phases only. The $c / a$ ratios of the $\omega$ phase remain very close to 0.613 in all aging temperatures (Hickman 1968, 1969a, b).

The alloy Ti-12Nb exhibits $\alpha^{\prime \prime}$ and $\omega$ phases in the $\beta$ STWQ condition. As mentioned above, the martensitic $\alpha^{\prime \prime}$ phase observed in the $\beta$ STWQ condition is unstable and can transform to $\alpha$ and $\alpha+\beta$ phases. The presence of $\alpha^{\prime \prime}$ phase in aged specimens of the alloy $\mathrm{Ti}-12 \mathrm{Nb}$ at 350 and $450^{\circ} \mathrm{C}$ is probably due to only partial transformation of the $\alpha^{\prime \prime}$ phase to $\alpha$ and $\beta$ phases. Further increase in aging temperature $\left(550^{\circ} \mathrm{C}\right)$ results in complete transformation of $\alpha^{\prime \prime}$ phase to $\alpha$ and $\beta$ phases and $\omega$ to $\alpha$ phase, thereby the aged microstructure consists of $\alpha$ and $\beta$ phases only. 
The behaviour of $\mathrm{Ti}-16 \mathrm{Nb}$ alloy during aging is also the same except that the $350^{\circ} \mathrm{C}$ aged specimen exhibit $\alpha^{\prime \prime}, \beta$ and $\omega$ phases (table 4 ). The absence of $\alpha$ phase (unlike the alloy $\mathrm{Ti}-12 \mathrm{Nb}$ ) in this specimen can probably be attributed to the small volume fraction of $\alpha$ phase which cannot be detected by XRD due to low intensity and also overlapping peaks. Further, increase in aging temperature $\left(450^{\circ} \mathrm{C}\right)$ exhibits $\alpha, \alpha^{\prime \prime}, \beta$ and $\omega$ phases (similar to the alloy $\mathrm{Ti}-12 \mathrm{Nb}$ ) and finally, aging at $550^{\circ} \mathrm{C}$ results in $\alpha$ and $\beta$ phases.

Balcerzak and Sass (1972) studied the formation of $\omega$ phase in as-quenched and aged specimens of $\mathrm{Ti}-\mathrm{Nb}$ alloys ranging from 18 to 40 -atom $\% \mathrm{Nb}$. They have observed an equiaxed $\omega$ phase in as-quenched specimens. The continuous aging has increased the size of the particles and evolved into an ellipsoidal shape. The competition between $\alpha$ and $\omega$ phases in metastable $\beta$ matrix has been studied during isothermal aging by Moffat and Larbalestier (1988). It has been shown that the aging temperature is the key factor that determines which phase will precipitate first in the quenched specimen. Aging at temperatures below $400^{\circ} \mathrm{C}$ results in extensive $\omega$ phase precipitation while at high temperatures $\left(\geq 400^{\circ} \mathrm{C}\right)$, exhibits $\alpha$ precipitation. The $\omega$ phase is metastable with respect to $\alpha$ phase. The $\alpha$ phase nucleates independently on existing $\omega$ precipitate and grows at the expense of the $\omega$ precipitate.

The aging behaviour of the present alloys in the quenched condition is quite different than those of the above-mentioned alloys. The quenched alloys consist of $\alpha$ or $\alpha^{\prime \prime}$ and $\omega$ phases depending on the $\mathrm{Nb}$ concentration unlike the metastable $\beta$ phase. The aging at low temperature initially transforms $\alpha$ phase to $\alpha$ and $\beta$ phases and $\omega$ forms from $\beta$ phase. On the other hand, aging at higher temperatures $\left(550^{\circ} \mathrm{C}\right)$ transforms existing $\omega$ phase to $\alpha$ phase. Since $\omega$ phase is associated with high hardness and brittleness, low temperature aging at which the $\omega$ phase formed is generally not carried out in titanium alloys (Duerig et al 1980). However, presence of $\omega$ phase can help in achieving fine distribution of $\alpha$ phase on subsequent aging or heat treatment at slightly higher temperatures (Silcock 1958).

3.4b $\alpha+\beta$ solution treatment: $\quad$ Aging of $\alpha+\beta$ STWQ specimens at $350^{\circ} \mathrm{C}$ does not introduce significant changes in the microstructures. However, fine scale microstructural changes may be occurring in the transformed $\beta$ phase, which can only be observed by TEM. Aging at $450^{\circ} \mathrm{C}$ further refines the microstructures due to fine precipitation of $\alpha$ phase (figure 16). Further increase in aging temperature $\left(550^{\circ} \mathrm{C}\right)$ introduces slightly coarse microstructures than those of $450^{\circ} \mathrm{C}$ aged specimens.

XRD studies of the aged specimens reveal the presence of $\alpha, \beta$ and $\omega$ phases at $350^{\circ} \mathrm{C}$ in all the three alloys (table 4). Further increase in aging temperature (450 and $550{ }^{\circ} \mathrm{C}$ ) shows the presence of $\alpha$ and $\beta$ phases. It appears that increase in aging temperature from 350 to $450^{\circ} \mathrm{C}$ has introduced fine $\alpha$ precipitates in the microstructure due to $\omega \rightarrow \alpha$ transformation. As a result, $450^{\circ} \mathrm{C}$ aged specimens consist of a very fine microstructure. It is very difficult to conclude anything about the transformation of $\alpha^{\prime \prime}$ to $\alpha$ or $\alpha+\beta$ in the present study since some amount of $\beta$ phase is already present in as quenched specimens. The
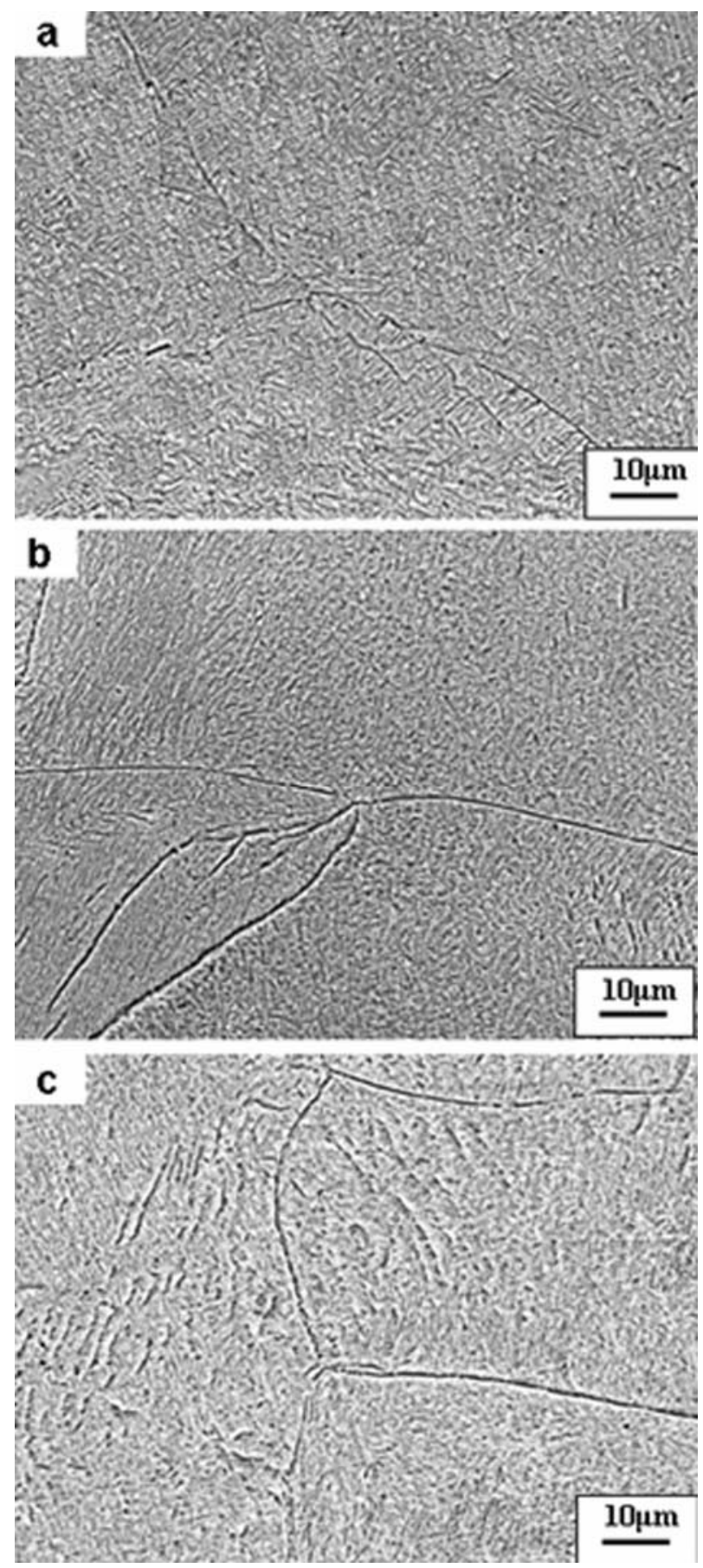

Figure 16. BSE SEM microstructures of $\alpha+\beta$ solution treated $\left(680^{\circ} \mathrm{C}, 1 \mathrm{~h}\right.$ and $\left.\mathrm{WQ}\right)$ and aged at $450^{\circ} \mathrm{C}, 24 \mathrm{~h}$ and $\mathrm{AC}$ (A2) alloys: (a) Ti-8Nb, (b) Ti-12Nb and (c) Ti-16Nb. 
presence of $\alpha$ and $\beta$ phases in all the alloys in the $550^{\circ} \mathrm{C}$ aged specimens indicates that only coarsening of existing phase occurs during aging.

The lattice parameters of all the phases in the $\alpha+\beta$ STWQ are given in table 6 . The lattice parameters of the $\alpha$ phase remains nearly constant in the aged specimens. The $c / a$ ratio of $\omega$ phase is very close to $0 \cdot 613$. There is a slight increase in the lattice parameter of $\beta$ phase with increase in aging temperature, which can be attributed to the change in composition during aging.

\section{Conclusions}

(I) The alloy $\mathrm{Ti}-8 \mathrm{Nb}$ exhibits $\alpha$ and $\beta$ phases while the alloys $\mathrm{Ti}-12 \mathrm{Nb}$ and $\mathrm{Ti}-16 \mathrm{Nb}$ show the presence of $\alpha^{\prime \prime}$ and $\beta$ phases in the as-cast and hot-rolled conditions. The presence of $\alpha^{\prime}$ phase in the as-cast and hot-rolled specimens can be attributed to high $\mathrm{Nb}$ content.

(II) The alloy $\mathrm{Ti}-8 \mathrm{Nb}$ shows $\alpha^{\prime \prime}$ phase and the alloys $\mathrm{Ti}-$ $12 \mathrm{Nb}$ and $\mathrm{Ti}-16 \mathrm{Nb}$ exhibit $\alpha^{\prime \prime}$ and $\omega$ phases in $\beta$ STWQ condition. The $\omega$ phase observed in latter two alloys is due the presence of high $\mathrm{Nb}$ concentration.

(III) The alloy $\mathrm{Ti}-8 \mathrm{Nb}$ shows the presence of $\alpha, \beta$ and $\omega$ phases while the alloys $\mathrm{Ti}-12 \mathrm{Nb}$ and $\mathrm{Ti}-16 \mathrm{Nb}$ exhibit $\alpha$, $\alpha^{\prime \prime}, \beta$ and $\omega$ phases in $\alpha+\beta$ STWQ condition.

(IV) High temperature aging results in $\alpha$ and $\beta$ phases.

(V) All the three alloys exhibit the presence of $\alpha, \beta$ and $\omega$ phases in $\beta$ STFC and $\alpha+\beta$ STFC conditions.

(VI) The presence of $\omega$ phase in the solution-treated condition depends on cooling rate and $\mathrm{Nb}$ content while in aged specimens depends on aging temperature as well as $\mathrm{Nb}$ concentration.

\section{Acknowledgements}

(AKS) and (SB) are grateful to the Ministry of Defence, Government of India, for financial support. We are grateful to Dr G Malakondaiah, Director, Defence Metallurgical Research Laboratory (DMRL), Hyderabad for his encouragement and support. We extend our thanks to Dr T K Nandy for many fruitful discussions.

\section{References}

Balcerzak A T and Sass S L 1972 Metall. Trans. 31601

Banumathy S, Mandal R K and Singh A K 2009 J. Appl. Phys. 106093518

Brown A R G, Clark D, Eastabrook J and Jepson K S 1964 Nature 201914

Boyer R, Welsch G and Collings E W 1994 Titanium alloys, materials properties handbook (Materials Park, OH: ASM International)

Collings E W 1984 Physical metallurgy of titanium alloys (OH: American Society of Metals)

Davis R, Flower H M and West D R F 1979 J. Mater. Sci. 14 712

Duerig T W, Terlinde G T and Williams J C 1980 Titanium 80. Science and Technology (eds) H Kimura and O Izumi (New York: The Metals Society-American Institute of Mining, Metallurgical and Petroleum) 2, 1299

Eylon D, Fujishiro S, Postans P J and Froes F H 1984 J. Met. 1 55

Geetha M, Singh A K, Muraleedharan K, Gogia A K and Asokamani R 2001 J. Alloys and Compds. 329264

Geetha M, Singh A K, Gogia A K and Asokamani R 2004 J. Alloys Compds 384131

Hickman B S 1968 J. Inst. Met. 96330

Hickman B S 1969a J. Mater Sci. 4554

Hickman B S 1969b Trans. Metall. Soc. AIME 2451329

Jepson K S, Brown A R G and Gray J A 1970 The science and application of titanium: Proc. first int. conf. on titanium (eds) R I Jaffee and W E Promisel (London: Pergamon Press) pp. $677-690$

Lagaree K 1989-1993 PKSFAReg, U.S. Patent, Registered Version 2.04, PKWARE Inc.

Moffat D L and Larbalestier D C 1988 Metall. Trans. A19 1677,1687

Murakami Y 1980 Titanium 80. Sci. and Technol. 1153

Murray J L 1987 Phase diagrams of binary titanium alloys (Metals Park, Ohio: ASM International) pp. 188-194

Silcock J M 1958 Acta Metall. 6481

Singh A K, Ramachandra C, Tavafoghi M and Singh V 1993 J. Mater. Sci. Lett. 129697

Sugimoto T, Komatsu S, Kamei K, Yoshida H and Murakami Y 1980 Titanium 80, Science and technology (eds) H Kimura and O Izumi (New York: The Metals Society-American Institute of Mining, Metallurgical and Petroleum) 4, pp. 2981-2990

Young M, Levine E and Margolin H 1974 Met. Trans. 51891 